This item was submitted to Loughborough's Research Repository by the author.

Items in Figshare are protected by copyright, with all rights reserved, unless otherwise indicated.

Non-newtonian mixed elastohydrodynamics of differential hypoid gears at high loads

PLEASE CITE THE PUBLISHED VERSION

http://dx.doi.org/10.1007/s11012-013-9857-x

PUBLISHER

(C) Springer

VERSION

AM (Accepted Manuscript)

LICENCE

CC BY-NC-ND 4.0

REPOSITORY RECORD

Mohammadpour, Mahdi, Stephanos Theodossiades, Homer Rahnejat, and T. Saunders. 2019. "Nonnewtonian Mixed Elastohydrodynamics of Differential Hypoid Gears at High Loads". figshare.

https://hdl.handle.net/2134/14303. 
This item was submitted to Loughborough's Institutional Repository (https://dspace.lboro.ac.uk/) by the author and is made available under the following Creative Commons Licence conditions.

\section{creative
commons}

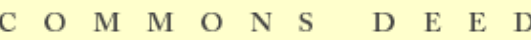

Attribution-NonCommercial-NoDerivs 2.5

You are free:

- to copy, distribute, display, and perform the work

Under the following conditions:

Attribution. You must attribute the work in the manner specified b the author or licensor.

Noncommercial. You may not use this work for commercial purposes.

No Derivative Works. You may not alter, transform, or build upon this work.

- For any reuse or distribution, you must make clear to others the license terms of this work.

- Any of these conditions can be waived if you get permission from the copyright holder.

Your fair use and other rights are in no way affected by the above.

This is a human-readable summary of the Leqal Code (the full license).

\section{Disclaimer 만}

For the full text of this licence, please go to: http://creativecommons.org/licenses/by-nc-nd/2.5/ 


\title{
Non-Newtonian Mixed Elastohydrodynamics of Differential Hypoid Gears at High Loads
}

\author{
M. Mohammadpour ${ }^{*}$, S. Theodossiades ${ }^{*}$, H. Rahnejat ${ }^{*}$ and T. Saunders** \\ ${ }^{*}$ Wolfson School of Mechanical \& Manufacturing Engineering, \\ Loughborough University, Loughborough, UK \\ ** Ford Engineering Research Centre, Dunton, Laindon, Essex, UK \\ Tel: $+44(0) 1509227664$ \\ Fax: $+44(0) 1509227648$ \\ Email: S.Theodossiades@Lboro.ac.uk
}

\begin{abstract}
:
Prediction of friction and transmission efficiency are design objectives in transmission engineering. Unlike spur and helical involute gears, there is a dearth of numerical analysis in the case of hypoid gear pairs. In particular, it is important to take into account the side leakage of the lubricant from the contact as the result of the lubricant entrainment at an angle to the elliptical contact footprint. In the automobile differential hypoid gears, high loads result in non-Newtonian behaviour of the lubricant, which may exceed its limiting shear stress, a fact which has not been taken into account in the open literature. This results in conditions which deviate from observed experimental tractive behaviour. The paper takes into account these salient practical features of hypoid gear pair analysis under high load. It highlights a non-Newtonian shear model, which limits the lubricant shear behaviour. Prediction of friction and transmission efficiency is in line with those reported in the literature.
\end{abstract}

Keywords: Automobile differential; hypoid gear pairs; non-Newtonian limiting shear; elastohydrodynamic lubrication; transmission efficiency
Abbreviations
Roman Symbols
A
$A_{a}$ 
b

D

$E_{r}$

$E_{p}$

$E_{w}$

$E^{2}$

F

$F_{a}$

$f_{b}$

$f_{v}$

G

$h$

$h_{c 0}$

$h_{c 0 \infty}$

$m$

$m^{*}$

$n_{g}, n_{p}$

$n_{\text {major }}, n_{\text {minor }}$
: Contact semi-minor half-width

: Deborah number

: Reduced elastic modulus of the contact:

$\pi /\left(1-v_{p}^{2} / E_{p}\right)+\left(1-v_{w}^{2} / E_{w}\right)$

: Young's modulus of elasticity of the pinion gear material

: Young's modulus of elasticity of the gear

wheel material

: $E_{r} / \pi$

: Contact load per meshing teeth pair (obtained through tooth contact analysis)

: Asperity load share

: Boundary friction contribution

: Viscous friction contribution

: Lubricant shear modulus

: Film thickness

: Central contact oil film thickness

: Central film thickness for a flooded inlet

: Inlet boundary parameter

: Starvation demarcation boundary parameter

: Unit vectors along the gear wheel and the pinion gear axes

: Unit vectors along the major and minor axes of the elliptical footprint 


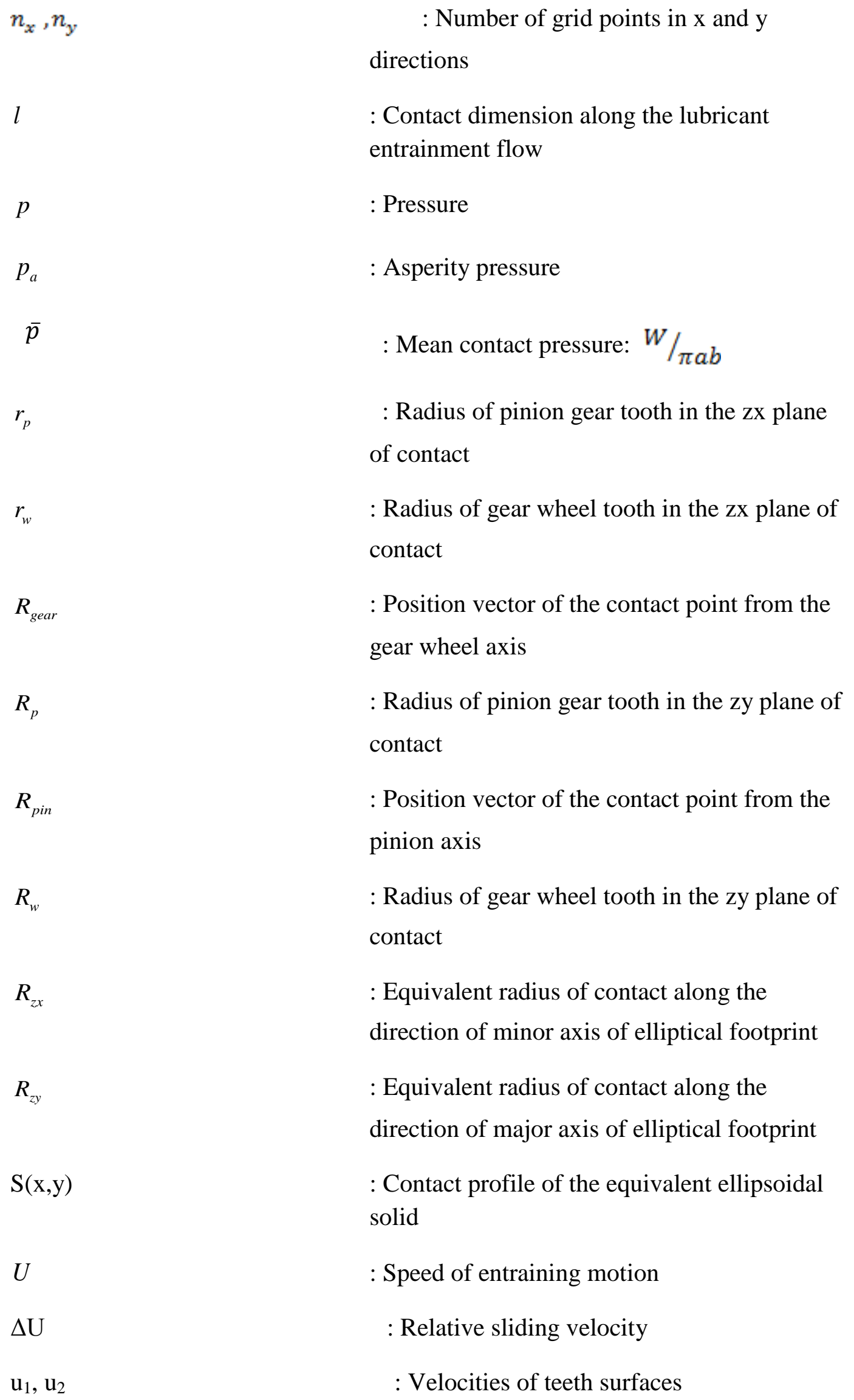
contact

: Position vector of the contact point from the gear wheel axis

: Radius of pinion gear tooth in the zy plane of contact

: Position vector of the contact point from the pinion axis

: Radius of gear wheel tooth in the zy plane of contact

: Equivalent radius of contact along the direction of minor axis of elliptical footprint

: Equivalent radius of contact along the direction of major axis of elliptical footprint : Contact profile of the equivalent ellipsoidal solid

: Speed of entraining motion

: Relative sliding velocity

: Velocities of teeth surfaces 


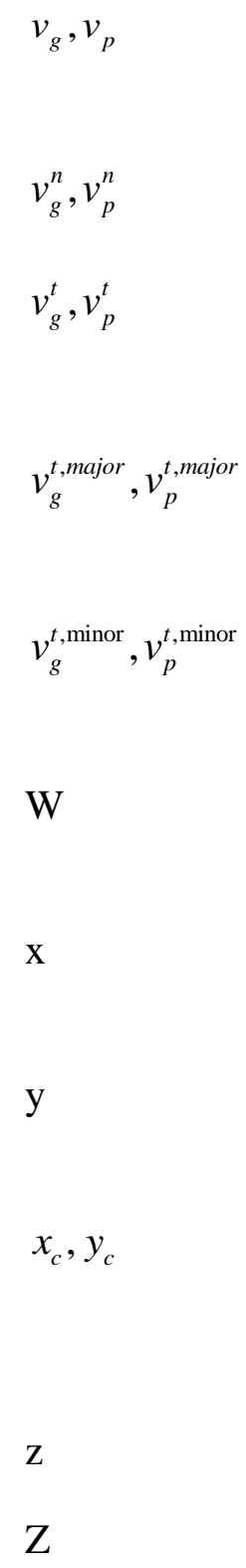

\section{Greek symbols:}

$\alpha$

$$
\beta
$$$$
\dot{\gamma}
$$

$\dot{\gamma}_{e}$

$\dot{\gamma}_{v}$

$\delta$

$\varepsilon_{p}$
: Spatial velocity of the point of contact on gear wheel and on the pinion

: Normal components of $v_{g}, v_{p}$

: Tangential (surface) components of $v_{g}, v_{p}$

: Components of $v_{g}^{t}, v_{p}^{t}$ along the major axis of the elliptical footprint

: Components of $v_{g}^{t}, v_{p}^{t}$ along the minor axis of the elliptical footprint

: Calculated contact load (integrated pressure distribution)

: Direction/distance along the minor axis of the elliptical footprint

: Direction/distance along the major axis of the elliptical footprint

: Lubricant film rupture boundaries along minor and major axes of the elliptical footprint

: Orthogonal direction to the plane of contact

: Piezo-viscosity index

: Lubricant pressure-viscosity coefficient

: Average asperity summit radius

: Shear rate

: Elastic shear rate

: Viscous shear rate

: Contact deflection

: Error in pressure convergence 


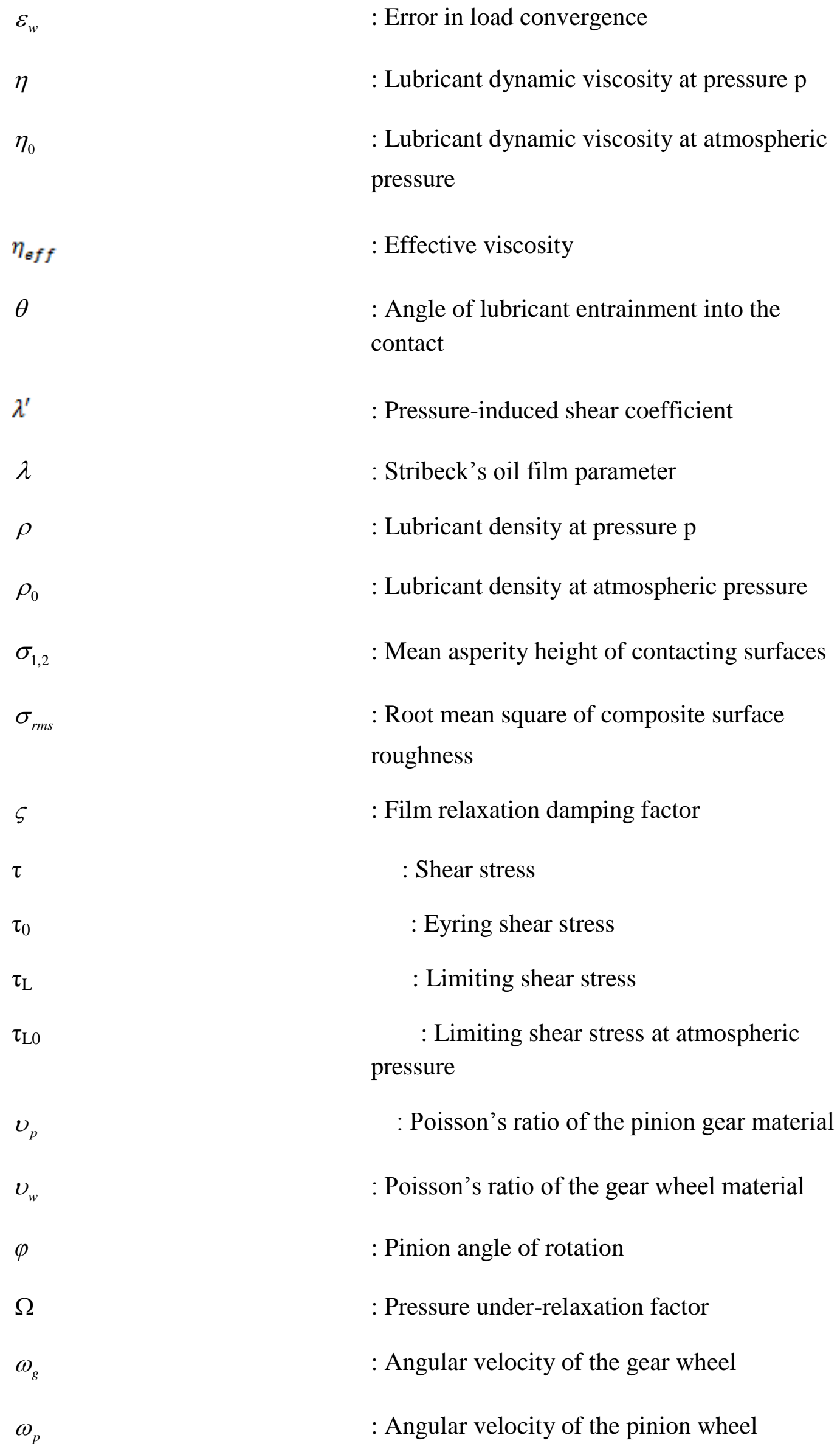

: Error in load convergence

: Lubricant dynamic viscosity at pressure $\mathrm{p}$

$\eta_{0}$

: Lubricant dynamic viscosity at atmospheric pressure

: Effective viscosity

$\theta$

: Angle of lubricant entrainment into the contact

: Pressure-induced shear coefficient

: Stribeck's oil film parameter

$\rho$

: Lubricant density at pressure $p$

$\rho_{0}$

: Lubricant density at atmospheric pressure

$\sigma_{1,2}$

: Mean asperity height of contacting surfaces

: Root mean square of composite surface roughness

: Film relaxation damping factor

: Eyring shear stress

: Limiting shear stress

: Limiting shear stress at atmospheric pressure

: Poisson's ratio of the pinion gear material

: Poisson's ratio of the gear wheel material

: Pinion angle of rotation

: Pressure under-relaxation factor

: Angular velocity of the gear wheel

: Angular velocity of the pinion wheel 


\section{1- Introduction}

Vehicle development is now driven by two over-riding objectives; fuel efficiency and reduced emissions. In the past couple of decades a trend towards compact and light weight constructions with improved combustion efficiency has attracted most attention. In general, the result has been significantly improved output power-to-weight ratio vehicles of all classes, but at the expense of a plethora of noise and vibration concerns, generally referred to as NVH (Noise, Vibration and Harshness) [1]. NVH refinement is as much a customer perceived quality issue as fuel efficiency and emission levels. In fact, recent trends have shown a direct link between NVH performance, fuel efficiency and emissions. Paradoxically, for lightly damped drivetrain systems [2] this link is friction.

In drivetrains, friction is required for effective tractive action to transmit the engine power to the driven wheels. Friction also consumes some of the engine order vibration energy, which is responsible for most of the NVH phenomena [3]. Thus, friction acts as an energy sink, hence improving upon the lightly damped nature of the powertrain system. The role of lubricant can be crucial in the attenuation of vibration through viscous shear, as well as efficient transmission of power through traction [4 - 6]. It should be noted that the lubricant would be subject to changes in the regime of lubrication in the variously loaded conjunctions as shown by De la Cruz et al [7]. Thin films are often subject to mixed thermo-elastohydrodynamic conditions with friction being as a result of viscous shear of a lubricant film, as well as asperity interactions on the contiguous contacting pairs. In transmission systems, the shear of lubricant film may be assumed to be Newtonian, except for thin adsorbed films at the asperity summits [7]. The same is not always the case in highly loaded contacts of hypoid gear pairs of differentials, subject to significant shear, where a non-Newtonian regime of lubrication is prevalent and an appropriate lubricant rheological model should be used.

Significant changes in contact kinematics and loading during meshing result in the formation of thin elastohydrodynamic films, which are often insufficient to guard against direct interaction of ubiquitous asperities on the meshing surfaces. Therefore, often a mixed regime of lubrication would be prevalent, with a thin lubricant film subject to non-Newtonian shear. Hence, the use of a constant coefficient of friction to represent contact conditions in some studies $[4,5]$ is inappropriate. Alternatively, some earlier works have made use of empirical formulae to represent the coefficient of friction as a function of system parameters $[8,9]$. In recent times a similar approach has been used by He et al [10], Velex et al [11, 12], and Kar and Mohanty [13], with friction described as a function of the length of the line of contact in their analyses of spur or helical gear teeth meshing.

For hypoid gear pairs, it is more appropriate to represent the meshing of gear teeth pairs as lubricated conjunctions. Then, the thickness of a film of lubricant can be predicted, prior to ascertaining the regime of lubrication and thus the contributions 
due to viscous shear and any boundary interactions in the same manner as that proposed by De la Cruz et al [7] for helical gears. This analytical treatment is highlighted by Karagiannis et al [14] using the Grubin's extrapolated oil film thickness equation as a function of contact load and sliding velocity [15]. Karagiannis et al [14] predicted thin thermo-elastohydrodynamic films, which are subjected to non-Newtonian shear and of insufficient thickness to guard against asperity interactions on the meshing teeth pairs. Whilst the use of an extrapolated equation reduces the computation times for transmissions with several teeth pairs in simultaneous mesh, such equations do not often accurately represent the prevailing contact conditions in gear meshing problems.

Although the gear lubrication problem has received considerable attention since Ertel and Grubin's discovery of the mechanism of elastohydrodynamic lubrication, there are only very few recent contributions which combine tooth contact analysis or gear dynamics with lubricated conjunctions. De la Cruz et al [7] class this approach as tribo-dynamics. The study by the authors was concerned with the meshing of helical gears of automobile transmissions. The typical contact footprint for such helical gear teeth pairs is a long and narrow rectangular strip, which is usually approximated by an elastic line contact $[7,16]$.

For hypoid gears, it is necessary to use the method of tooth contact analysis (TCA) to determine the contact footprint shape and orientation [17]. Xu and Kahraman [18] assumed a line contact approximation in their numerical solution of Reynolds equation for hypoid gear teeth pair meshing. Surface velocities of the contacting teeth were evaluated with the aid of Rodrigues' formula, using the angular velocities and the surface curvatures. However, it is important to note that a line contact footprint is idealised. A more realistic elliptical point contact would exist in practice. A recent work by Kolivand et al [19] provides a regressed equation for friction, based on mixed elastohydrodynamic conditions and non-Newtonian shear of thin lubricant films. However, the line contact assumption was retained. Simon [20] presented a thermo-elastohydrodynamic analysis of hypoid gear pairs. $\mathrm{He}$ considered the contact as an elliptical point contact. Similarly, Mohammadpour et al [21] also used an elliptical contact footprint, providing an isothermal Newtonian elastohydrodynamic solution of hypoid gears at high loads, representative of automobile differentials and with angled lubricant flow into the contact. They also accounted for inlet starvation, which is another important facet of lubrication of gears, using Hamrock and Dowson's inlet starvation boundary [22]. The contact footprint is elliptical in shape for bevel and hypoid gears as shown also by Gabiccini et al [23] and others [24]. However, the elliptical footprint shape truncates at the tip or root tooth contact and loses its symmetry. The footprint shape resembles a tear-drop shape [24]. This problem is somewhat alleviated with profiling of teeth.

Simon [20] assumed the entrainment flow vector to be along the minor axis of the contact ellipse. This ignores the side leakage of lubricant from the contact and leads to the breach of continuity of flow condition. Also, simulation studies were carried out at low input torque, not representative of vehicle differentials. There is experimental evidence of angled entrainment flow, for example by Gohar [25], as well as numerical predictions by Jalali-Vahid et al [26]. These indicate the importance of including the correct contact footprint shape, as well the the directions of entraining motion and side-leakage of the lubricant. The assumption 
of a line contact footprint can be considered as reasonable in circumstances which promote an elliptical point contact of quite large aspect ratio, usually at relatively low load.

The work in [21] is extended here to include non-Newtonian shear of thin films at high loads, whilst retaining the angled lubricant entrainment flow into the rolling and sliding contact and using realistic inlet boundary conditions. Furthermore, the non-Newtonian shear behaviour variously reported for hypoid gear pairs makes use of the lubricant shear rate as a function of hyperbolic sine function of shear stress, which allows the limiting shear stress of the lubricant to be exceeded. It also fails to explain the experimental measurements of prevailing gear traction. In the discussions on the work reported by Bair and Winer [27], Tewaarverk indicated that Eyring's model is only valid for low pressures according to the available experimental traction data. The present paper introduces a traction regime to overcome this problem. Finally, unlike the solutions reported thus far, it is important to use the Ree-Eyring form of Reynolds equation for non-Newtonian lubricant flow. The formation of a thin non-Newtonian elastohydrodynamic films promote direct interaction of meshing teeth surfaces. Therefore, the contact load is carried by the lubricant film as well as by a small proportion of surface asperities of the counterfaces. Rough surface interactions is represented by the Greenwood and Tripp [28] model. Therefore, there are significant additions to the solution of hypoid gear pairs hitherto reported in literature.

\section{2- Hypoid gear pair model}

The developed model of a pair of hypoid gears comprises contacts of a number of teeth pairs in simultaneous mesh. For the automotive differential investigated here 1-3 pairs of teeth are in simultaneous contact at the various stages of meshing. It is, therefore, necessary to calculate the contact geometry, kinematics and load share for each pair through tooth contact analysis. This is carried out using the Calyx software [18, 29]. A full description of the approach followed is given in Mohammadpour et al [21] with a brief description provided in section 2.3.

Contacts of meshing teeth pairs are subject to elastohydrodynamic regime of lubrication. Thin elastohydrodynamic films in hypoid gears of automotive differentials are subject to relatively high loads, undergoing combined rolling and sliding motions. These conditions lead to non-Newtonian shear of the lubricant. Therefore, a suitable non-Newtonian model for lubricant shear behaviour should be used (section 2.1), as well as a suitable form of the Reynolds equation (section 2.2).

\section{1- Non-Newtonian lubricant shear characteristics}

Newtonian models of lubricant shear are accurate for the prediction of EHL film thickness, but fail to explain the measured experimental traction data (mainly by disc machines) for thin films, especially at high loads [30 - 32]. In particular, 
these models neither account for the variation of traction with rolling speed nor for its variation with the speed of sliding. The shear stress is directly proportional to the rate of shear at low sliding velocities, but at higher sliding velocities the shear rate increases more rapidly than the resulting stress. It is known that the critical factor is the magnitude of shear stress, not the rate of shear. This critical value of stress, known as the Eyring shear stress $\tau_{0}$ [33], depends on the applied pressure and the lubricant molecular size, according to Hirst and Moore [34]. Above the Eyring shear stress the non-linear relationship between shear stress and shear rate deviates significantly from the idealised linear Newtonian model. Under EHL, Eyring shear stress is often exceeded and this is liable to influence the generated pressures and traction performance of the contact.

In general, three regions of lubricant performance may be considered: (i)- at low sliding speeds the shear behaviour may be regarded as Newtonian, (ii)- at high sliding speeds shear heating can become important and (iii)- in the intermediate speed region, the lubricant behaviour exceeds Newtonian characteristics but it cannot be explained in terms of thermal effects [35]. In this intermediate region the fluid behaviour is assumed to be as the result of two potential non-Newtonian effects:

(a)- Viscoelastic behaviour, in which the shear of a lubricant film is assumed to be partly due to its viscoelastic nature according to Johnson and Tevaarwerk [30]. The results obtained by Hirst and Moore [34] reinforce this hypothesis. Thus, the shear rate is noted as:

$$
\dot{\gamma}=\dot{\gamma}_{e}+\dot{\gamma}_{v}=\frac{1}{G} \dot{\tau}+\dot{\gamma}_{v}
$$

Therefore, the complex behaviour of fluid is an interplay between the elastic term and the viscous term in equation (1). A more usual form of (1) is given in terms of Deborah number, $D$ as [32]:

$$
\dot{\gamma}=\frac{D}{\eta} \frac{\partial \tau}{\partial x}+\dot{\gamma}_{v}
$$

where: $D=\frac{\eta U}{G l}$ is the ratio of lubricant relaxation time, $\frac{\eta}{G}$ over its transit time through the contact $\frac{l}{U}$. When $D>>1$, the elastic term in (2) becomes significant. Then, the shear modulus of lubricant is given by $G \approx 0.1+3 \bar{p} \quad(\bar{p}=W / \pi a b$ is the average contact pressure), according to various disc machine experiments [32, 36]. Hirst and Moore [34] suggest that the transition to viscoelastic behaviour occurs at pressures above the lubricant solidification pressure, when the lubricant may be considered as an amorphous solid.

(ii) Non-linearity of shear stress-strain rate behaviour: Hirst and Moore [34] and Johnson and Tevaarwerk [30] have pointed out that the lubricant viscoelastic behaviour must be non-linear. This has resulted in proposing various non-linear models, where as yet no agreed model is generally adopted. Lee and Hamrock [38] provide a good review of the various proposed models. 
A point of agreement between the research workers has been that the shear stress should not exceed a limiting value, $\tau_{L}$. This critical value of shear stress is regarded as a property of the lubricant at any specific pressure. Crook [39] tried to explain the limiting shear stress with the influence of shear heating for a Newtonian shear model. His theoretical results showed agreement with experiments at low and moderate contact pressures, but predicted very high traction coefficients at high pressures. Hirst and Moore [34] suggested that at lower pressures the viscosity of lubricant appears to fall when a critical shear stress is reached, whilst in the elastic region at higher pressures there appears to be an elastic limit.

Johnson and Tevaarwerk [30] proposed a relatively simple non-linear constitutive equation for the non-Newtonian shear behaviour of the lubricant in the form of a hyperbolic sine function. This model broadly describes the observed shear behaviour of the lubricant obtained through slide-roll experiments with disc machines. For the first time, the Eyring shear stress $\tau_{0}$ based on the energy barrier theory of Eyring [33] was included in a rheological model

$$
\dot{\gamma}_{v}=\frac{\tau_{0}}{\eta} \sinh \left(\frac{\tau}{\tau_{0}}\right)
$$

This model, widely used for non-linear, non-Newtonian traction [20, 32, 34, 40] does not include a limiting shear stress, $\tau_{L}$. Therefore, at high pressures the limiting shear can be exceeded. Bair and Winer [27] presented an alternative Maxwell model, based on their experimental observation. It is essentially an elastic-viscoelastic-plastic model. The model restricts the shear behaviour of the lubricant within its boundary limiting value. The problem with this model is the lack of real and applicable values for the limiting shear stress at different pressures, at least those available in the open literature. There is also an underlying presumption that viscoelastic behaviour occurs at relatively high slideroll ratios. However, high wear rates have also been noted for even low slide-roll ratios under tractive conditions [41], where one would normally assume Newtonian shear. Therefore, models based on a prescribed limiting shear stress may have their own limitations. The Johnson and Tevaarwerk [30] model (because of its relative simplicity) is well suited to numerical analysis. Therefore, it is used in this study as well.

\section{2- The elastohydrodynamic conjunction}

Conry et al [42] developed the Reynolds-Eyring equation based on the Johnson and Tevaarwerk's shear model [30]. They neglected lubricant elastic shear for situations where large strain rates occur $(D<1)$. Conry et al [42] utilized their model to study elastohydrodynamics of line contacts. The Ree-Eyring fluid model was used by Wang et al [43] for thermo-elastohydrodynamics of line contacts, showing a reduction in the central film thickness with increased thermal loading and sliding motion. 
The first two-dimensional non-Newtonian model was reported by Kim and Sadeghi [44], who used a multi-grid technique to simultaneously solve the Eyring stress-modified Reynolds equation and the elasticity potential equation. They found that an increasing slide-roll ratio had a negligible effect on the minimum film thickness, but as it was noted in the earlier one-dimensional solutions, increased sliding produced a significant reduction in the pressure spike at the exit constriction. However, the work in [44] was limited to slide-roll ratios less than 21 per cent.

The current study uses the approach of Conry et al [42] and extends it to the case of elliptical point contact with angled lubricant entrainment into the contact, as is the case for hypoid gear teeth pairs through mesh (Mohammadpour et al [21]). Thus:

$$
\frac{\partial}{\partial x}\left[\frac{\rho h^{3}}{\eta} s(x) \frac{\partial p}{\partial x}\right]+\frac{\partial}{\partial y}\left[\frac{\rho h^{3}}{\eta} s(y) \frac{\partial p}{\partial y}\right]=12 U\left\{\cos \theta \frac{\partial}{\partial x}[\rho h]+\sin \theta \frac{\partial}{\partial y}[\rho h]\right\}
$$

where $\theta$ is the entrainment flow angle to the minor axis of the elliptical contact footprint (Fig. 1) [23] and $U$ is the speed of entraining motion: $U=\frac{1}{2}\left(u_{1}+u_{2}\right)$. Any localised changes in the speed of entraining motion due to angled flow are considered small due to the minute contact footprint size. In reality, there will be small variations along the contact footprint. However, the rate of change of the lubricant entrainment velocity is small compared to the rate of change of the principal radii of curvature through mesh. In fact, the Reynolds equation based on laminar flow, assumes an instantaneous steady speed of entraining motion. The form of (4) omits the squeeze film effect as the result of approach and separation of gear teeth pairs. This is a transient effect which often increases the load carrying capacity of the contact, as noted by Gohar and Rahnejat [32]. This effect has been taken into account for film thickness estimation in different applications such as for cam-tappet contact $[45,46] . s(\mathrm{x})$ and $s(\mathrm{y})$ are dimensionless modifying parameters for lubricant viscosity to comply with the non-Newtonian hyperbolic sine model:

$$
\begin{aligned}
& s(x)=\left\{1+\left(\frac{\eta \Delta U \cos \theta}{\tau_{0} h} \frac{\xi_{x}}{\sinh \xi_{x}}\right)^{2}\right\}^{1 / 2}\left\{\frac{3\left(\xi_{x} \cosh \xi_{x}-\sinh \xi_{x}\right)}{\xi_{x}^{3}}\right\} \\
& s(y)=\left\{1+\left(\frac{\eta \Delta U \sin \theta}{\tau_{0} h} \frac{\xi_{y}}{\sinh \xi_{y}}\right)^{2}\right\}^{1 / 2}\left\{\frac{3\left(\xi_{y} \cosh \xi_{y}-\sinh \xi_{y}\right)}{\xi_{y}^{3}}\right\}
\end{aligned}
$$

where:

$$
\xi_{x}=\frac{h}{2 \tau_{0}} \frac{\partial p}{\partial x} \text { and } \xi_{y}=\frac{h}{2 \tau_{0}} \frac{\partial p}{\partial y}
$$


An effective viscosity is defined as:

$$
\eta_{\text {eff }}=\frac{\eta}{s(x)} \text { or } \eta_{e f f}=\frac{\eta}{s(y)}
$$

The value of limiting shear stress is obtained as [47]:

$$
\tau_{L}=\tau_{L 0}+\lambda^{\prime} p
$$

The combined non-Newtonian shear model is used. In this approach the value of shear stress is continuously monitored during the meshing cycle for any pair of meshing teeth using (10). If the value of shear stress exceeds that obtained from (9), then its value is replaced by the limiting shear stress at the mean contact pressure $\bar{p}$.

$$
\tau=\eta_{e f f} \dot{\gamma}_{v}=\frac{\eta_{e f f} \Delta U}{h}
$$

It should be noted that the Eyring stress also changes with pressure as well as the limiting shear stress [34]. These effects are neglected in the current analysis. This is because the high value of shear stress reached under the simulated conditions exceeds the value of Eyring shear stress used in the analysis. The shear stress is usually around the lubricant's limiting shear stress. At lower shear, the higher pressures lead to increased Eyring stress. Consequently, for a specific condition the fluid behaviour can change to Newtonian or vice versa. Due to the prevailing high shear stress conditions in the current analysis, the Eyring shear stress is considered to remain constant.

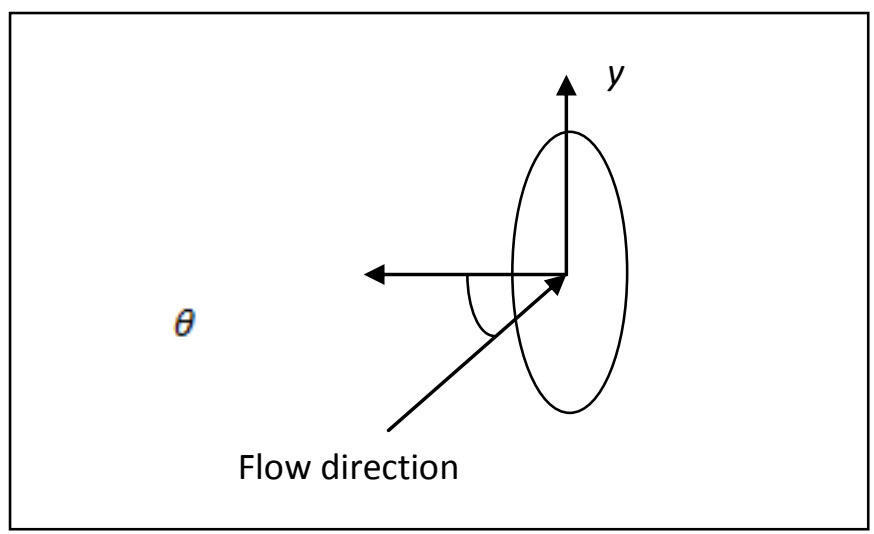

Fig.1 Representation of an elliptical point contact conjunction with angled entrainment flow 
The film thickness at any location within the contact, at any instant of meshing, is given by:

$$
h(x, y)=h_{c 0}+s(x, y)+\delta(x, y)
$$

The current analysis represents the surface roughness of the contiguous solid teeth using the Greenwood and Tripp [28] model, described later. Alternatively, The film thickness equation may include the amplitude of roughness on the surfaces by representative statistical functions. In such an approach the Ree-Eyring form of Reynolds equation (4) should be represented in terms of the average flow model described by Patir and Cheng [48]. Either approach has its own merits and drawbacks. The current approach is preferred in the current analysis, because it incorporates details of asperity geometry and deformation characteristics. The use of Greenwood and Tripp [28] also enables extension of boundary interaction model to elasto-plastic deformation of the asperities in a later stage.

In equation (11), the undeformed parabolic conjunctional profile is: $s(x, y)=\frac{x^{2}}{2 R_{z x}}+\frac{y^{2}}{2 R_{z y}}$

$R_{z x}$ and $R_{z y}$ are the equivalent radii of contact of an ellipsoidal solid against a semi-infinite elastic half-space, representing the instantaneous contact of any pinion to gear wheel teeth pair in the planes $z x$ (along the minor axis of the contact ellipse) and $z y$ (along its major axis, fig. 2):

$$
\frac{1}{R_{z x}}=\frac{1}{r_{p}}+\frac{1}{r_{w}} \quad \text { and } \quad \frac{1}{R_{z y}}=\frac{1}{R_{w}}-\frac{1}{R_{p}}
$$

The instantaneous radii of pinion and gear teeth are determined through TCA (Mohammadpour et al [21], see section 2.3).

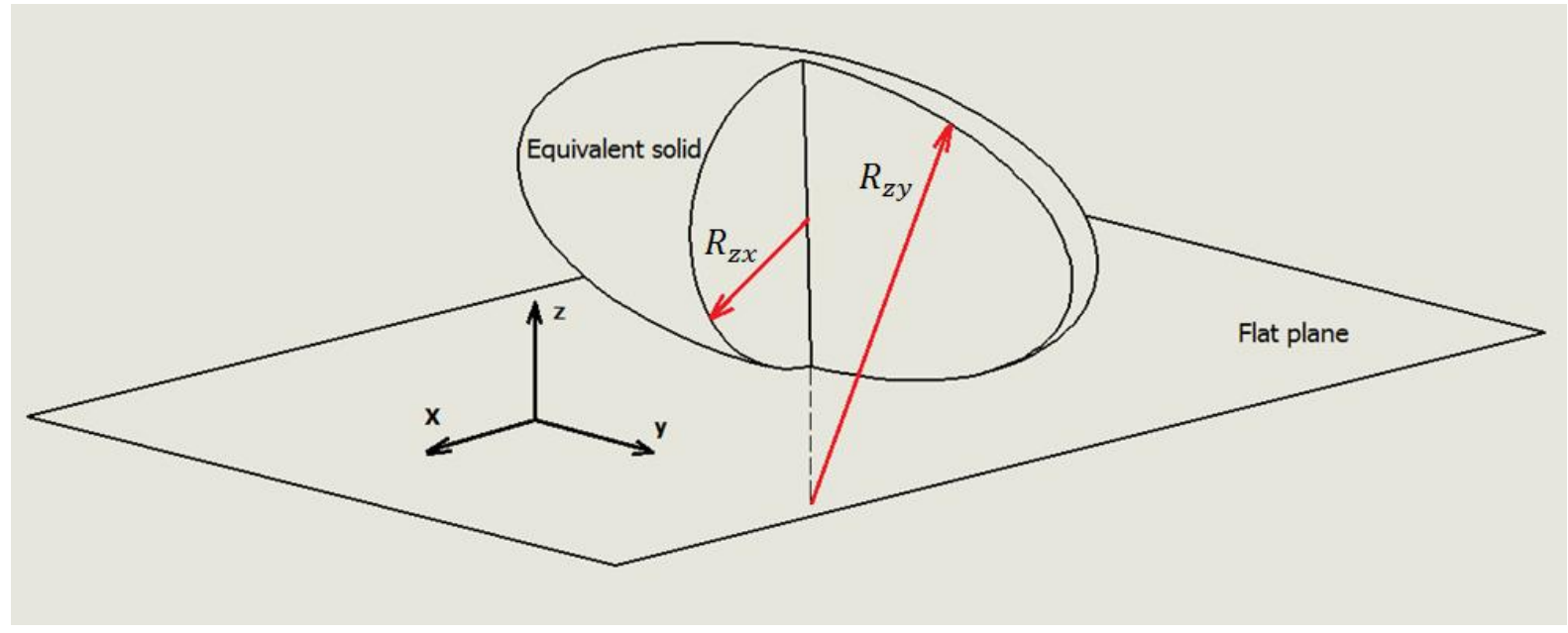

Fig.2 Contact Geometry of the equivalent ellipsoidal solid 
The localised contact deflection $\delta(x, y)$ is obtained by solution of the elasticity potential integral:

$$
\delta(x, y)=\frac{1}{E_{r}} \iint_{A} \frac{p\left(x_{1}, y_{1}\right) d x_{1} d y_{1}}{\sqrt{\left(x-x_{1}\right)^{2}+\left(y-y_{1}\right)^{2}}}
$$

where $(x, y)$ represents a point where the deflection of the semi-infinite elastic half-space of reduced elastic modulus $E_{r}$ is calculated due to any arbitrary pressure distribution $p\left(x_{1}, y_{1}\right)$.

To obtain a solution to the EHL problem comprising (4) - (13), the lubricant rheological state is required:

For piezo-viscous lubricant behaviour [49]:

$$
\eta=\eta_{0} \exp \left\{\left[\left(\ln \eta_{0}+9.67\right) \times\left(1+5.1 \times 10^{-9} p\right)^{Z}\right]-\left[\ln \eta_{0}+9.67\right]\right\}
$$

where, $Z=\frac{\alpha c_{p}}{\left(\ln \eta_{0}+9.67\right)}=\frac{\alpha}{5.1 \times 10^{-9}\left(\ln \eta_{0}+9.67\right)}$, as $c_{p}=1.96 \mathrm{MPa}$

For lubricant density variation with pressure [50]:

$$
\rho=\rho_{0}\left(1+\frac{0.6 \times 10^{-9} p}{1+1.7 \times 10^{-9} p}\right)
$$

A key assumption made in this paper is isothermal conditions. Lubricant viscosity clearly reduces with temperature and hence its load carrying capacity [32]. Consequently, a thicker lubricant film thickness would result in practice than that obtained with an isothermal assumption here.

\subsection{1- Boundary Conditions}

A fully flooded inlet boundary condition is assumed in the EHL analysis. This means:

$$
x \rightarrow-\infty, p \rightarrow 0 \quad \text { and } \quad y \rightarrow-\infty, p \rightarrow 0
$$

Hence, the inlet boundary should be set at a suitable distance away from the leading edge of the elliptical contact footprint. This distance is usually set at 4-5 times the contact footprint semi-half-width $[22,26]$ and changes with load in both 
directions: $m=x / b$ or $y / a$. The starvation boundary is also a function of the height of the lubricant film at the inlet $h_{c o \infty}$, which according to Birkhoff and Hays [51] is: $h_{c o 0} / h_{c o}=11.293$. The inlet boundary parameter $m$ must vary according to the load and speed combination, meaning that it should be set at the so-called starvation boundary. In this case the same assumption has been used as that in Mohammadpour et al [21], who use the starvation boundary parameters according to Hamrock and Dowson [22]:

$$
m^{*}=1+3.06\left[(R / \gamma)^{2} h_{c 0}\right]^{0.58}
$$

where for the flow component along the minor axis: $R=R_{z x}, \gamma=b$. While for that along the major axis: $R=R_{z y}, \gamma=a$. The inlet condition is set as $m=m^{*}$. The initial film thickness is estimated using Grubin's [15] film thickness equation, including the side-leakage correction factor obtained by Gohar [52]:

$$
h_{c 0} / R_{z x}=1.212\left(\alpha \eta_{0} U / R_{z x}\right)^{3 / 4}\left(W / E_{r} R_{z x}^{2}\right)^{-1 / 12}\left\{1+\frac{2}{3}\left(R_{z y} / R_{z x}\right)\right\}^{-2 / 3}
$$

The calculated inlet parameters are illustrated in Fig. 3 for the studied hypoid gear pair. The contact load is obtained as: $W=\int_{x=x_{i}}^{x_{c}} \int_{y=y_{i}}^{y_{c}} p d x d y$. The inlet boundaries given by $x_{i}$ and $y_{i}$ are set to Hamrock and Dowson [24] inlet boundary.

Ali et al [53] also provided a study of starved lubrication of non-conformal point contacts. Their work focuses on frictional effects of starvation. It presents an experimental and analytical results showing the relationship between friction under starved and fully flooded conditions. A similar approach for film thickness has been provided in [22].

The outlet boundary condition used is that of Swift [54] - Stieber [55]: $p=\partial p / \partial x=0$ at $x=x_{c}$ and $p=\partial p / \partial y=0$ at $y=y_{c}$, where the film rupture positions $x_{c}$ and $y_{c}$ are obtained by discarding any negatively generated pressures in the iterative numerical procedure. 


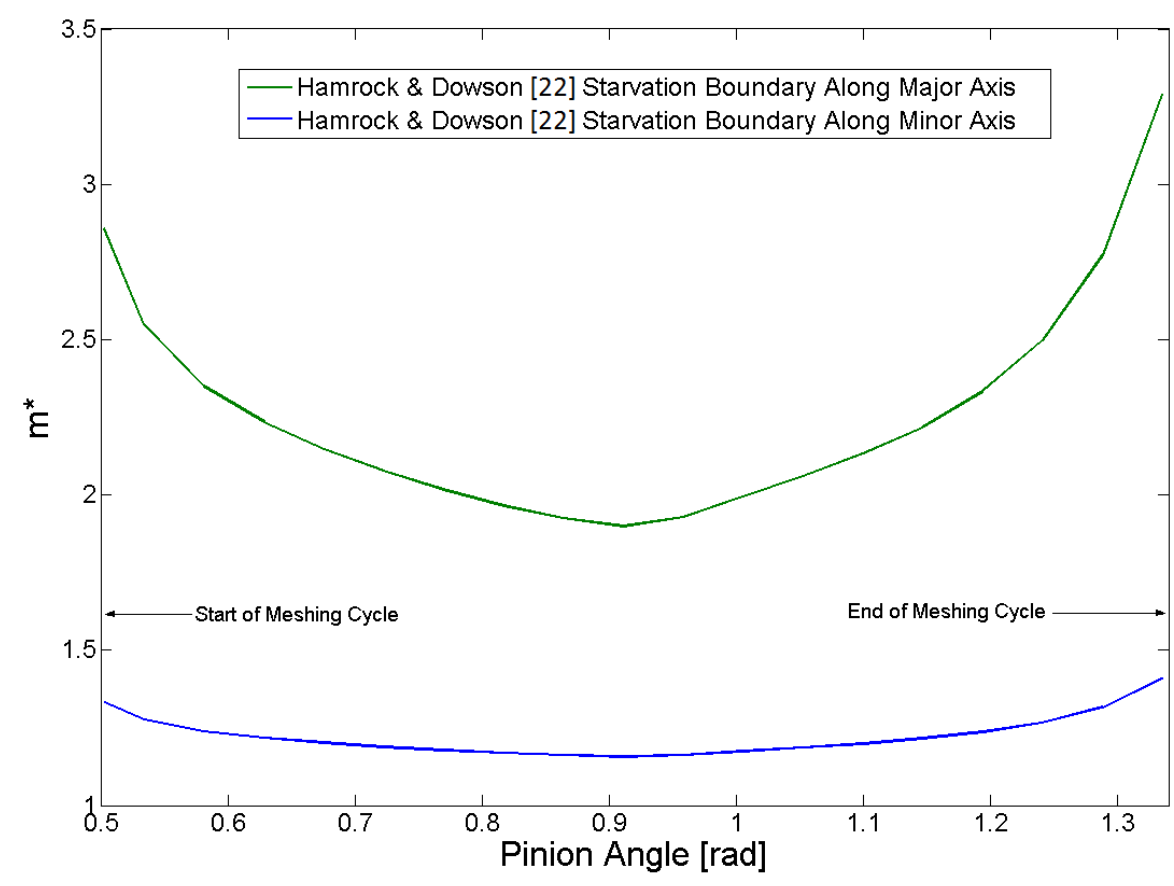

Fig.3 Starvation boundaries along minor and major axes

\section{3- Tooth contact analysis}

In gear applications and especially in hypoid gears, it is necessary to compute the principal contact radii of curvature of the pinion and gear wheel teeth through the meshing cycle. These are subsequently used to obtain the principal radii of the equivalent ellipsoidal solid in (12) at any instant during the meshing cycle for any conjugate teeth pair. One method of obtaining the principal radii for any teeth pair is through tooth contact analysis (TCA). The method is outlined in detail by Litvin and Fuentes [17]. At any instant of time in the differential hypoid gears several teeth pairs are in contact. TCA calculates the load share variation per teeth pair during meshing cycle, as well as the corresponding meshing stiffness and the static transmission error.

TCA analysis also provides the geometrical, kinematic and load data that are required for the EHL analysis. The contact load applied per teeth pair is a function of the dynamic response of the system. However, its distribution among teeth pairs in simultaneous contact is defined quasi-statically. The ratio of the applied load $F_{i}$ on a given flank under consideration (Fig. 4) to the total transmitted load $F_{t}(\mathrm{Xu}$ and Kahraman [18]) is called load factor and it is as a function of the pinion angle:

$$
\text { lf }=\frac{F_{i}}{F_{t}}
$$


A similar technique was followed for spur and helical gears by Vaishya and Singh [56] and He et al [10].

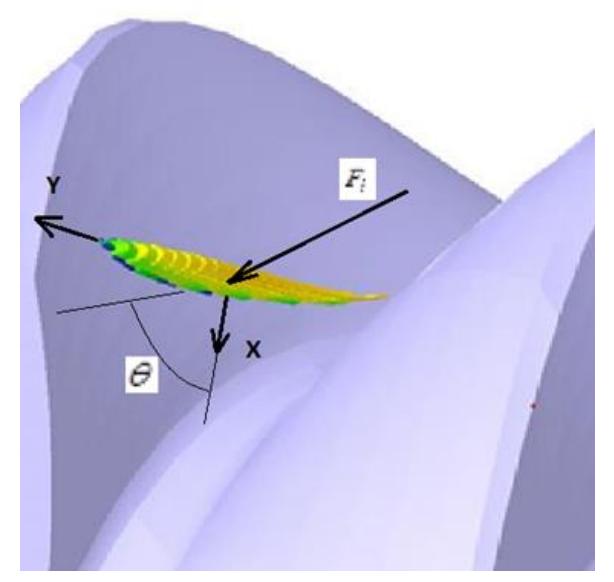

Fig.4 Contact footprint and direction of angled flow

It is also necessary to obtain the speed of lubricant entraining motion into the contact at any instant of time to be used in (4). The velocity of any point on the pinion and gear teeth in contact may be obtained as:

$$
v_{p}=\omega_{p}\left(n_{p} \times R_{\text {pin }}\right) \text { and } v_{g}=\omega_{g}\left(n_{g} \times R_{\text {gear }}\right)
$$

Where $n_{p}$ and $n_{g}$ are the unit vectors along the pinion and gear axes, respectively. $R_{\text {pin }}$ and $R_{\text {gear }}$ are the position vectors of the contact point with respect to the coordinate system attached to the axes of the pinion and gear, respectively. These velocities can be resolved along the normal direction ( $v_{p}^{n}$ and $v_{g}^{n}$ ) and along the tangential plane $\left(v_{p}^{t}\right.$ and $\left.v_{g}^{t}\right)$. The tangential components are used to obtain the rolling and sliding contact velocities. These components, as well as those along the major and minor axes of the Hertzian contact ellipse can be presented using vector dot products:

$$
v_{p}^{t, \text { major }}=v_{p} \bullet n_{\text {major }}, v_{g}^{t, \text { major }}=v_{g} \bullet n_{\text {major }}, v_{p}^{t, \text { minor }}=v_{p} \bullet n_{\text {minor }} \text { and } v_{g}^{t, \text { minor }}=v_{g} \bullet n_{\text {minor }}
$$

where, $v_{p}^{t_{\text {,major }}}$ and $v_{p}^{\text {t,minor }}$ are the components of the pinion surface velocities along the major and minor axis. $n_{\text {major }}$ and $n_{\text {minor }}$ are the unit vectors of the major and minor axis.

Thus, the speed of entraining motion along the minor and major axes of the elliptical footprint in Fig. 1 are obtained as:

$$
v_{r}^{\text {major }}=v_{p}^{t, \text { major }}+v_{g}^{t, \text { major }}=U \sin \theta
$$




$$
v_{r}^{\text {minor }}=v_{p}^{t, \text { minor }}+v_{g}^{t, \text { minor }}=U \cos \theta
$$

Clearly, the lubricant entrainment into the contact takes place at an angle to the minor axis of the Hertzian contact footprint:

$$
\theta=\tan ^{-1}\left(v_{r}^{\text {major }} / v_{r}^{\text {minor }}\right)
$$

Significant lubricant entrainment occurs along the major axis of the contact ellipse. The side-leakage flow has a significant effect on film thickness and should not be ignored. The precession of the contact footprint with respect to an assumed fixed lubricant velocity vector is as the result of combined rolling and sliding motion of teeth pairs through mesh. The variation in the aspect ratio is as the result of instantaneous contact geometry, being approximately proportional to $\left(\frac{R_{z x}}{k_{z y}}\right)^{-2 / 3}$. Note that the side leakage correction factor obtained by Gohar [52] is directly proportional to this ratio. The velocity of the side-leakage flow along the direction of major axis of the elliptical point contact is shown in table 2.

This may be appreciated by fixing the direction of lubricant entrainment and noting the orientation of the elliptical contact footprint with respect to it as a pair of teeth progresses through mesh (Fig. 5).

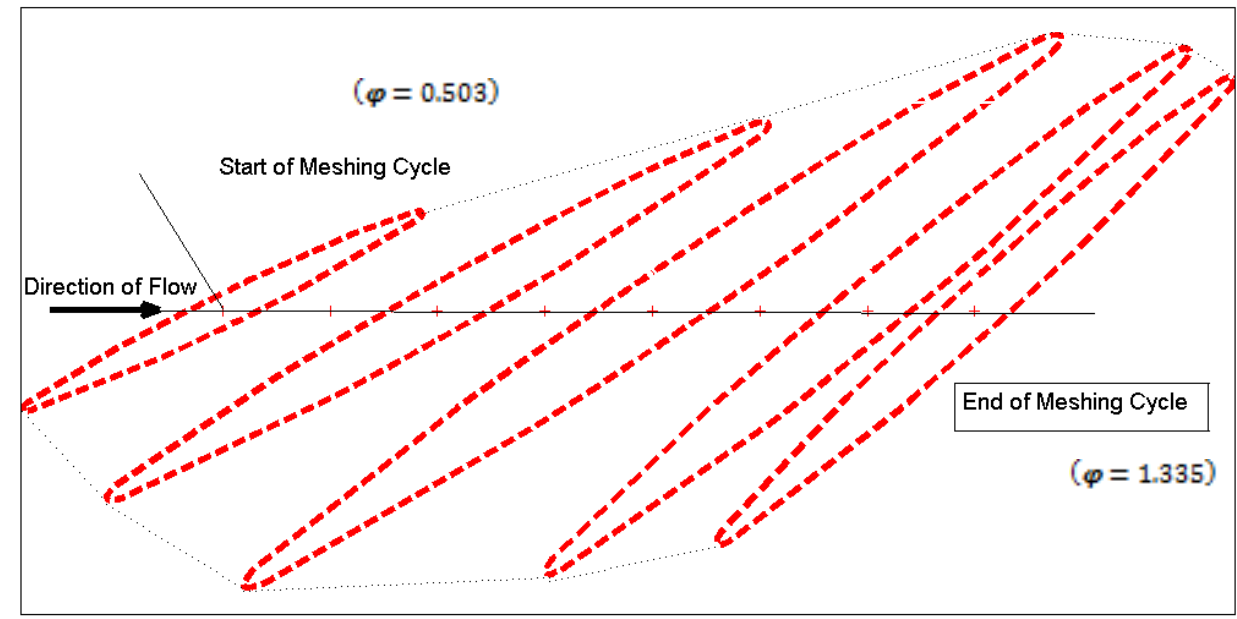

Fig.5 The processing elliptical footprint through a meshing cycle

\subsection{Method of solution of the EHL problem and convergence criteria}

Reynolds-Eyring (4) is discretised in the same manner as that described by JalaliVahid et al [57] and Mohammadpour et al [21]. The low line relaxation effective influence Newton-Raphson method with Gauss-Seidel iterations is used to 
describe the pressure at any nodal position $(i, j)$ with a computation grid covering the solution domain.

The iterative process comprises the following steps:

1- During meshing and at each pinion angle, $\varphi$, an initial guess is made for the central oil film thickness, using (17). The data for contact geometry, load and speed of entraining motion are obtained through TCA.

2- Using the film thickness obtained in step 1, the inlet boundary condition is set as $m=m^{*}$ for both the inlet boundaries ahead of the major and minor axes of the contact ellipse. A grid of $n_{x} \times n_{y}$ is used to cover the domain bounded by the inlet menisci along the $x$ (minor axis) and $y$ (major axis) and extend beyond the elliptical contact to include the conjunctional exit boundaries at the lubricant film rupture points; $x_{c}$ and $y_{c}$.

3 - The pressure distribution and the corresponding lubricant film contour are obtained by simultaneous solution of (4)-(15) in an iterative manner, where the convergence criteria in steps 4 and 5 should be met.

4- Pressure convergence is attempted as:

$$
\sum_{i} \sum_{j}\left|\frac{p_{i, j}^{k}-p_{i, j}^{k-1}}{p_{i, j}^{k}}\right| \leq \varepsilon_{p}
$$

where, $10^{-5} \leq \varepsilon_{p} \leq 10^{-4}$. In any iterative step the calculated value of shear stress is compared with the limiting shear stress obtained from equation (9). If the calculated value exceeds the limiting shear, then the effective viscosity is obtained from (10). This method is called the "Combined nonNewtonian Model". If pressure convergence is not achieved, then the generated pressures are under-relaxed as: $p_{i, j}^{k}=p_{i, j}^{k-1}+\Omega \Delta p_{i, j} \in i, j$. The under-relaxation factor is usually $0.01 \leq \Omega \leq 0.8$ and the steps 3-4 are repeated.

5- The second convergence criterion seeks to establish quasi-static balance between the applied load per teeth pair, $F_{n}$ and the lubricant reaction $W=\iint p d x d y+F_{a}$, where $F_{a}$ is the proportion of load carried by a small proportion of asperities, and given by equation (29) later. Thus, the load convergence criterion is:

$$
\left|\frac{F_{n}-W}{F_{n}}\right| \leq \varepsilon_{w}
$$

where, $0.001 \leq \varepsilon_{w} \leq 0.05$. If the criterion is not met, the central film thickness $h_{c o}$ is adjusted and the entire iterative process - steps (3) to (5) are repeated: 


$$
h_{c 0}^{l}=h_{c 0}^{l-1}\left(\frac{F_{n}}{W}\right)^{\varsigma}
$$

where, $-0.1 \leq \varsigma \leq 0.1$ is termed as damping factor.

In the above process, the indices $i, j$ refer to a computational grid position, $k$ denotes the pressure convergence iteration counter, $n$ any teeth pair and $l$ is the load convergence iteration counter.

6- After both convergence criteria are met, the entire process is repeated for the next value of the pinion angle. To observe the contact conditions for any pair of meshing teeth, the meshing cycle is sub-divided into 20 discrete steps of the pinion's rotation.

\section{3- Results and Discussion}

The current analysis investigates the contact conditions for a moderate to highly loaded hypoid gear pair of a vehicle's differential (Tables 1a and 1b). The results presented are for a typical gear meshing teeth pair cycle. These correspond to an engine torque of $144 \mathrm{Nm}$ at $2524 \mathrm{rpm}$. The transmission is engaged in the $5^{\text {th }}$ gear with a ratio of $0.702: 1$. These are representative conditions of a highway driving about $70 \mathrm{mph}$ speed for a light van or passenger car equipped with an engine similar to the characteristics given in appendix and with P205/65R15 BSW tyre. Table 2 lists the results of TCA for the load share of a contacting teeth pair, as well as the effective principal radii of contact through mesh. It also lists the speed of entraining motion of the lubricant into the contact along the minor and major axes of the Hertzian contact ellipse. These are the input to the elastohydrodynamic analysis. For this analysis, the computational finite difference domain is divided into $n_{x} \times n_{y}=60 \times 60$ finite intervals. Simulation studies were carried out on a $2.93 \mathrm{GHz}$ Pentium Intel 17 machine with the computational time for one point of the meshing cycle being approximately 5000 CPU seconds. Figure 6 shows the effect of computational grid size upon convergence for the high loaded condition in table 2. Grid sizes of 40X40, 50X50, 60X60, 70X70 and 80X80 were used. This is shown in the figure. Small variations in pressure distribution and film thickness can be observed. Therefore, a grid size of 60X60 is deemed as adequate. 


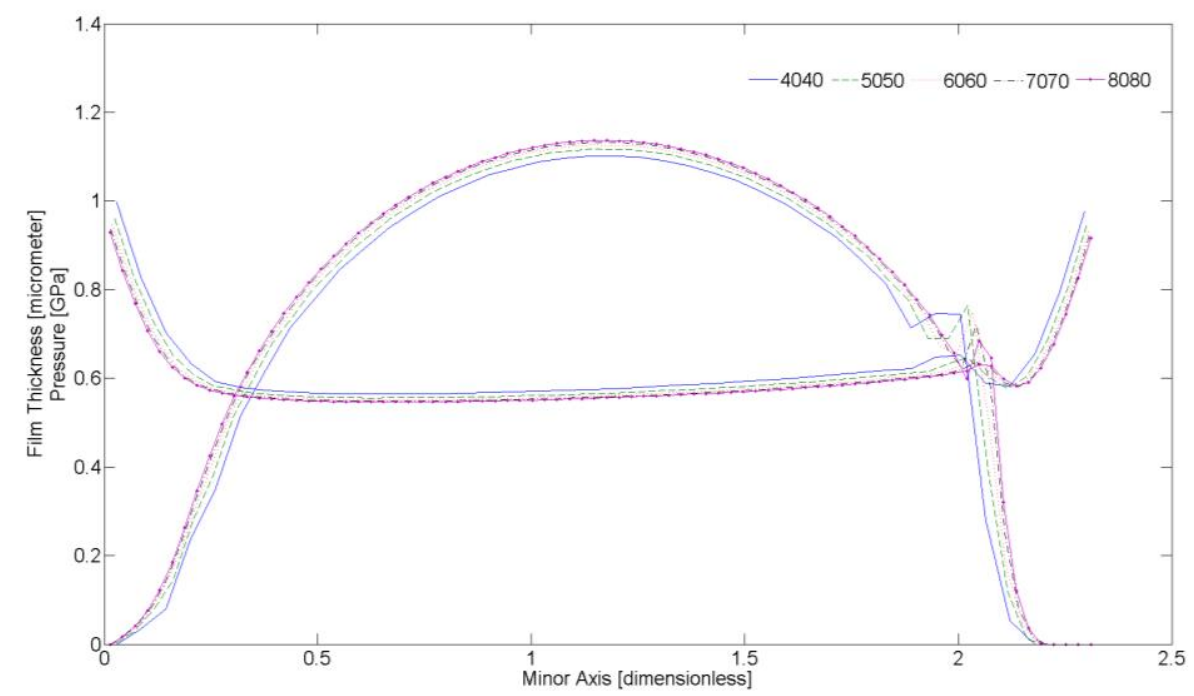

Fig.6 Grid convergence of the model

Referring back to table 2, the pinion angle in column 1 corresponds to the various instances of a gear teeth pair through mesh. In this case, for the teeth pair considered, the meshing cycle commences at the pinion angle of 0.503 radians and ends at the angle of 1.34 radians. Note that the entrainment flow velocity components along the major and minor axes of the elliptical point contact footprint are quite comparable. Therefore, both the assumption of a line contact analysis, as well as the simplifying assumption for the speed of entraining motion being along the minor axis - commonly used in the literature - are not justified. In fact, Fig. 7 shows significant slide-roll ratios for the aforementioned differential hypoid gear pair, and also well in excess of the analysis carried out by Kim and Sadeghi [44]. Table 2 also provides the principal radii of the equivalent ellipsoidal solid contacting an elastic half-space at any instant of time through mesh. These are required for the solution of the Reynolds-Eyring (4), as well as the initial guess values for the film thickness obtained from (17).

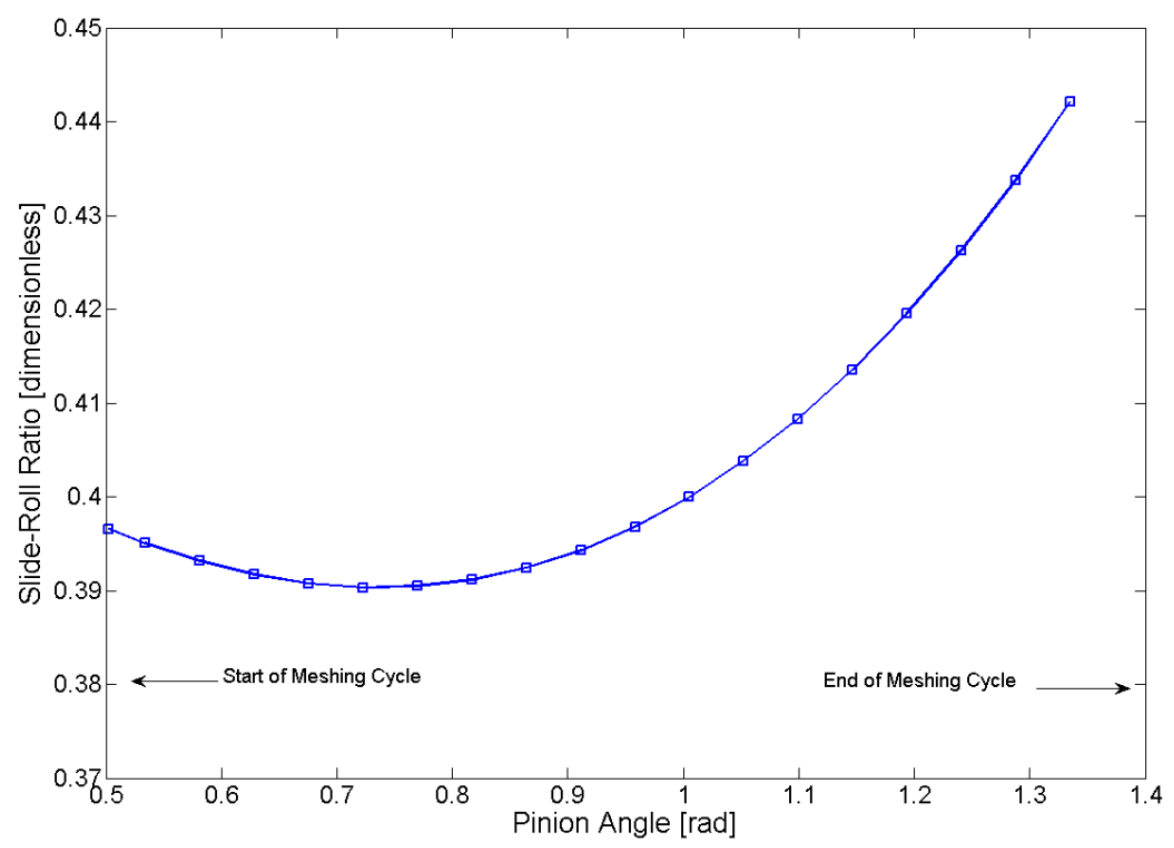


Fig.7 Contact kinematics under prescribed differential running conditions

Fig.s 8 and 9 show the pressure distribution and the corresponding film thickness contour for the pinion angle of 0.9582 . This is the point in the meshing cycle with the highest load share for the teeth pair considered, where the slide-roll speed ratio is 0.4 .

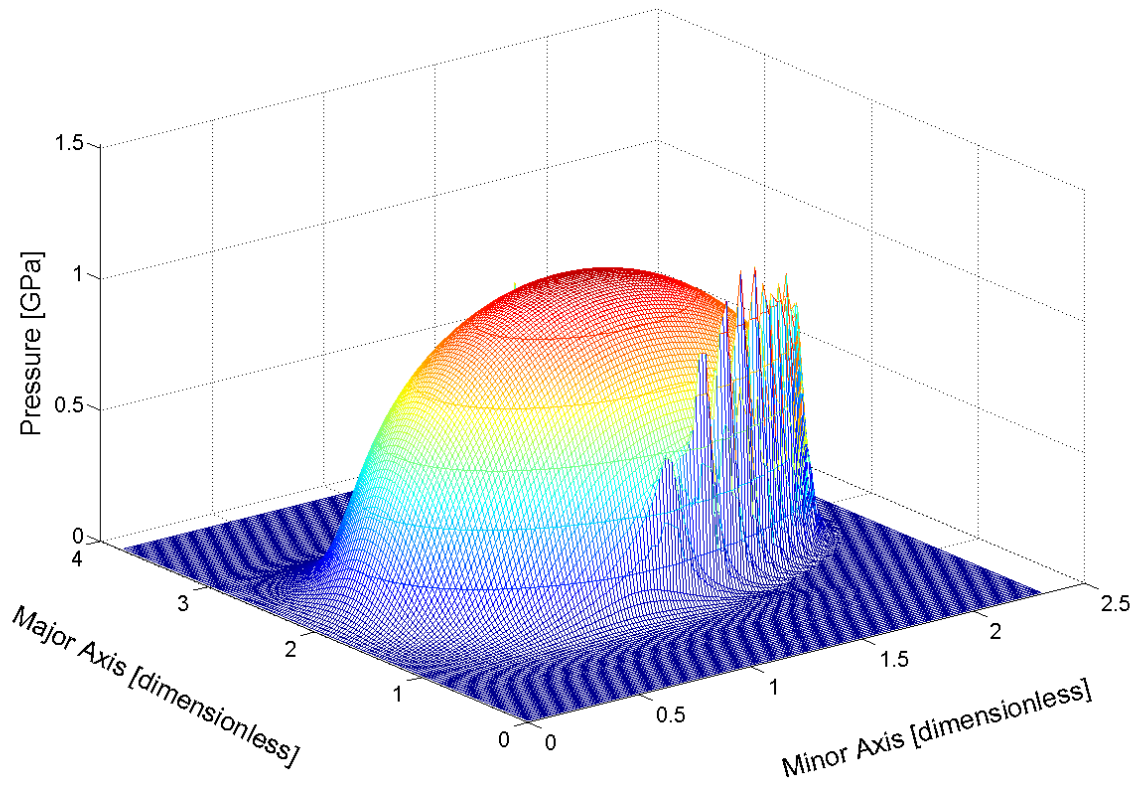

Fig.8 Three dimensional elastohydrodynamic pressure distribution (position of maximum contact load)

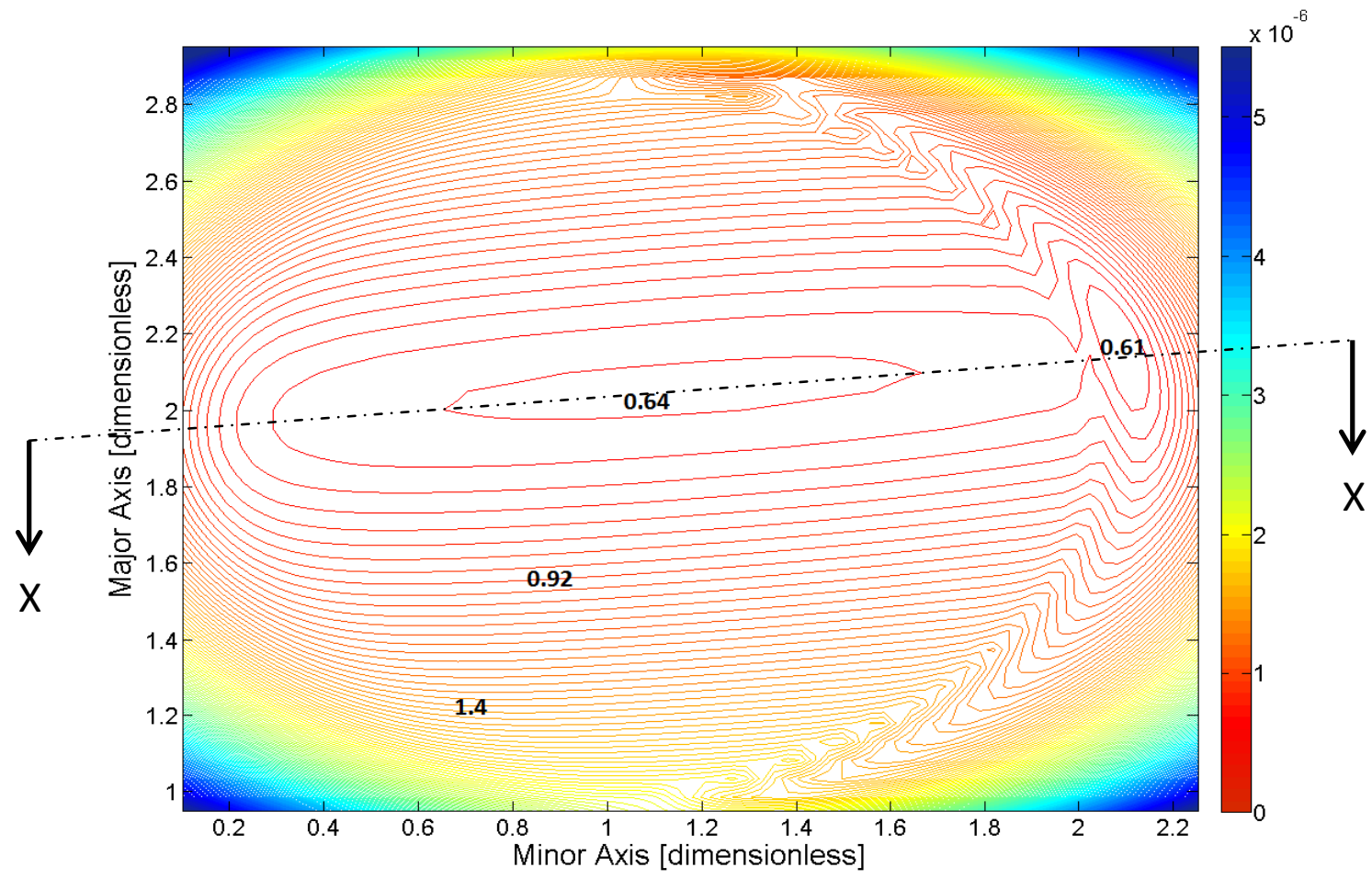

Fig.9 Lubricant film contour (position of maximum contact load) 
The maximum pressures are of the order of $0.8-1 \mathrm{GPa}$, with the minimum film thickness in the region of $0.5-0.6 \mu \mathrm{m}$. The island of minimum film thickness occurs in the exit constriction at the contact outlet and along the entrainment flow at an angle to the minor axis of the elliptical contact (along X-X). The minimum film thickness can be observed more clearly by a cut through this cross-section of the film contour (as shown in Fig. 10), and is around $0.55 \mu \mathrm{m}$. The root mean square surface roughness of the face-hobbed hypoid gears investigated here is approximately: $\sigma_{R M S}=\sqrt{\sigma_{1}^{2}+\sigma_{2}^{2}}=0.49 \mu m$. This yields a Stribeck oil film parameter of $\lambda=\frac{h_{\min }}{\sigma_{R M S}}=1.12$. Therefore, a mixed regime of lubrication would be expected.

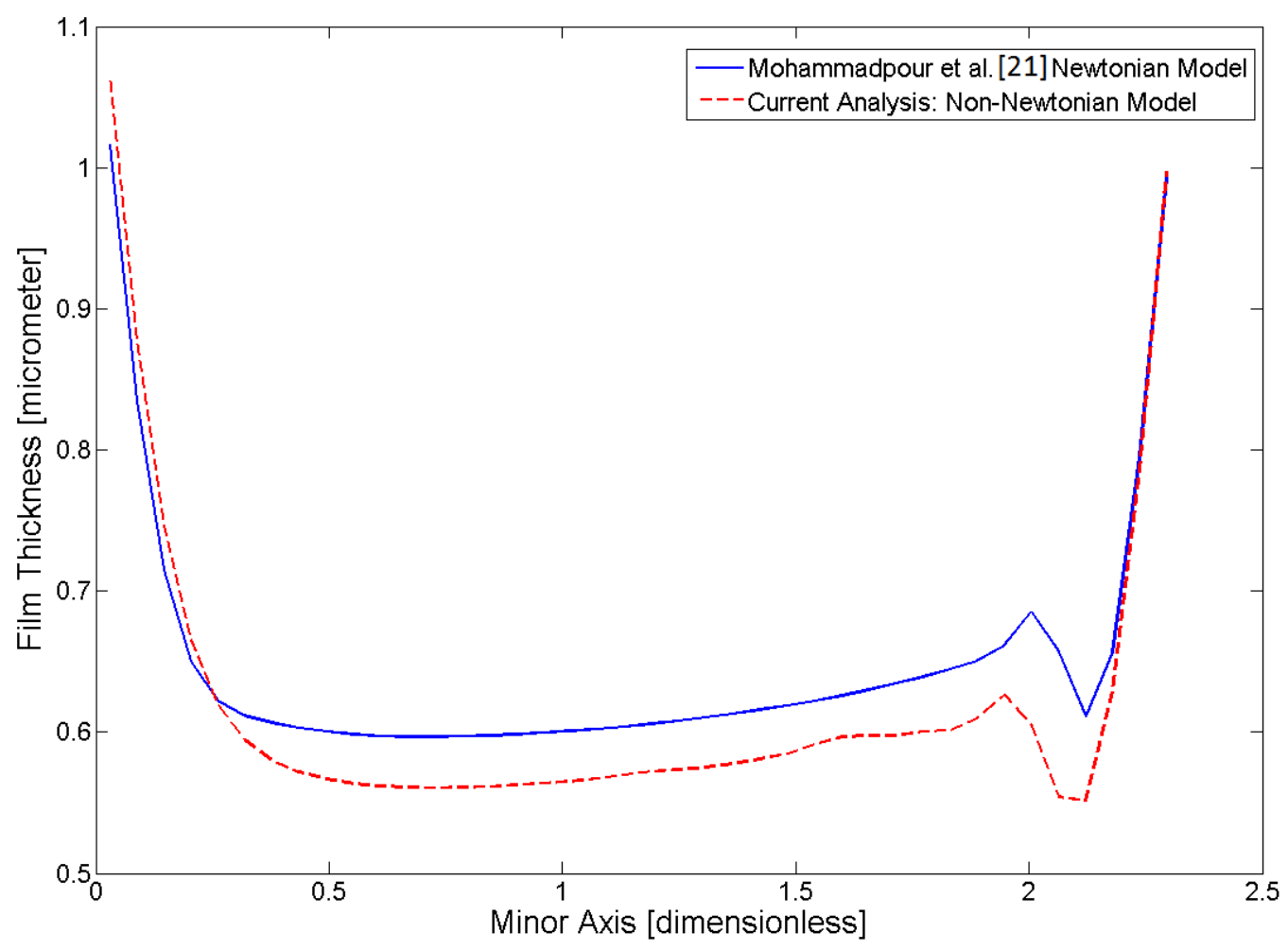

Fig.10 Elastohydrodynamic film shape along the section X-X' under Newtonian and non-Newtonian shear

Fig. 11 shows the shear stress variation within the contact under the same conditions. The non-Newtonian shear stress variation, based on the sine hyperbolic function (3) is also shown in the figure. It is clear that it exceeds the limiting shear stress throughout the contact domain at all values of generated pressure (9). The results using the proposed "combined non-Newtonian shear model" are also shown in the same figure, which confines the lubricant shear characteristics to the limiting shear stress. Additionally, the shear stress variation is shown, if Newtonian shear characteristics are to be assumed. Note that if that were to be the case, very high shear stresses, well in excess of the limiting shear stress are predicted, which have unrealistic values. Bair [58] presented viscosity measurements for a range of lubricants, including transmission fluids at pressures 
up to $1.4 \mathrm{GPa}$ and temperatures up to $165^{\circ} \mathrm{C}$. The results of Bair's viscometer measurements show that at fairly moderate pressures, the Newtonian assumption for lubricant behaviour yields excessive values for viscosity for the temperatures usually encountered in transmissions and far in excess of the limiting shear stress, similar to those shown in Fig. 11. The results obtained, using the "combined nonNewtonian Model" of the current analysis conform to the limiting shear stress value as shown in the figure throughout the meshing cycle. This observation seems to suggest that at least under the current assumed isothermal conditions, the contact conditions are confined to a narrow region of elastohydrodynamic behaviour and lubricant traction occurs at the limiting shear stress throughout the meshing cycle. These conditions can be confirmed by presenting the results on the Greenwood chart for fluid film regimes of lubrication (Fig. 12) and the traction chart of Evans and Johnson [36] (Fig. 13). In the Greenwood chart (Fig. 12), the elastic parameter is $G_{e}=W^{*} 8 / 3 / U^{* 2}$, while the viscous parameter is $G_{v}=G^{*} W^{* 3} / U^{* 2}$. Note that: $U^{*}=U \eta / E_{r} R_{z x}, W^{*}=W / E_{r} R_{z x}^{2}$ and $G^{*}=\alpha E_{r}$. Elastohydrodynamic conditions for contacts with significant slide-roll ratios at high loads are indicated by an increasing combination of $G_{e}$ and $G_{v}$. Fig. 13 confirms that except for the instances at the beginning and at the end of the meshing cycle, where lubricant shear behaviour tends to Newtonian conditions, the traction conditions remain close to the limiting Eyring shear, except at the highest loaded part of the cycle where there is a tendency towards viscoelastic behaviour of the lubricant. The hyperbolic sine shear characteristics adopted in the current analysis does not take into account the elastic contribution in this surmised viscoelastic behaviour. It is necessary to ascertain the significance of this finding with regard to the analysis carried out.

Furthermore, in figure 13 the tractive region referred to as "Eyring" implies the dependence of the Eyring shear stress upon the sliding velocity (variation along the ordinate). The dependence of Eyring shear stress upon the prevailing instantaneous sliding velocity is a function of the characteristic velocity of the process required to reach an activation energy to shear/dislocate a unit volume of the fluid/lubricant. A thermodynamic energy balance is required to establish the variation of Eyring shear stress with sliding velocity (Briscoe and Evans [47]). The current paper is an isothermal analysis, thus the Eyring shear stress is assumed to remain constant. 


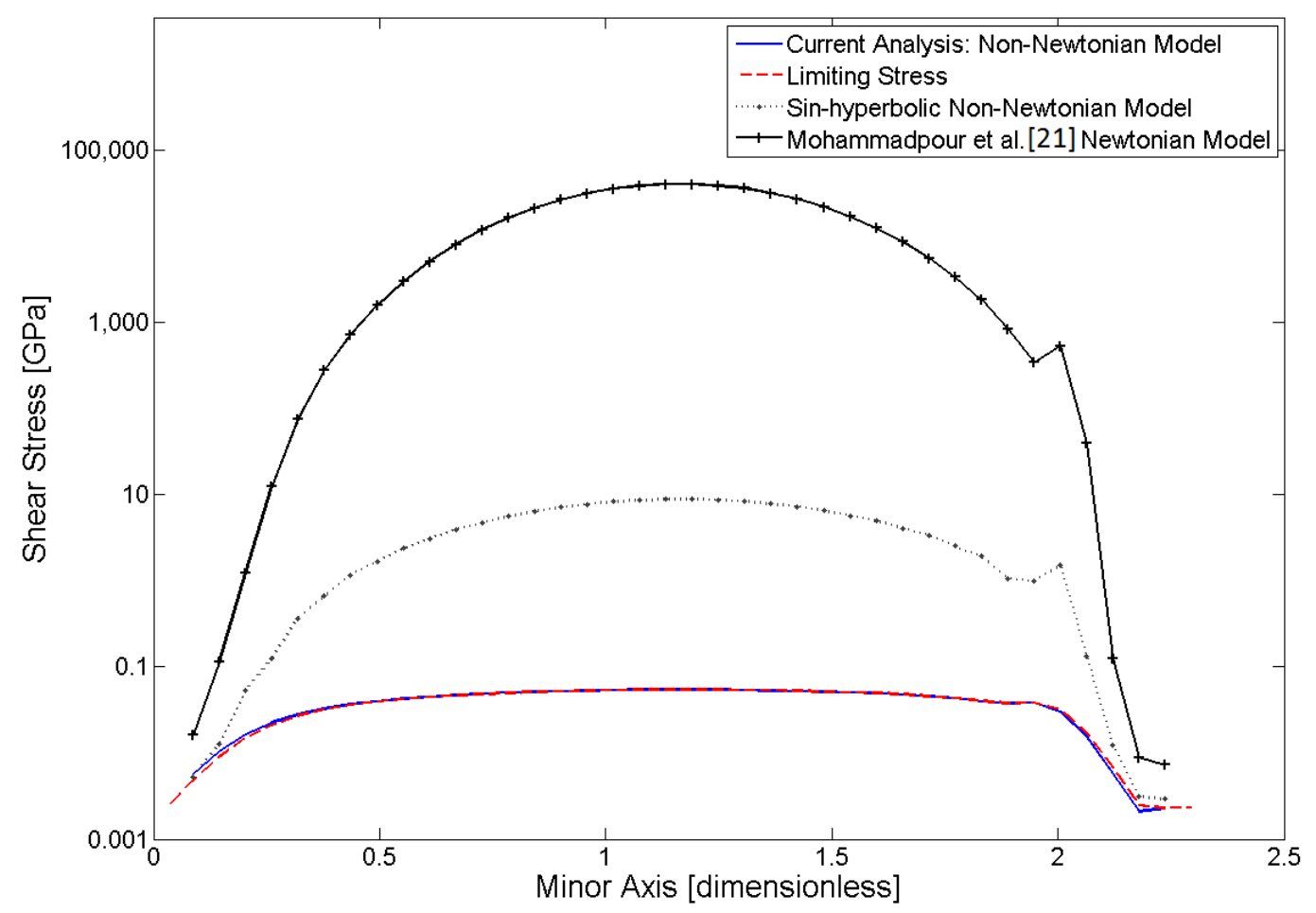

Fig.11 Shear stress variation within the contact at the maximum meshing load

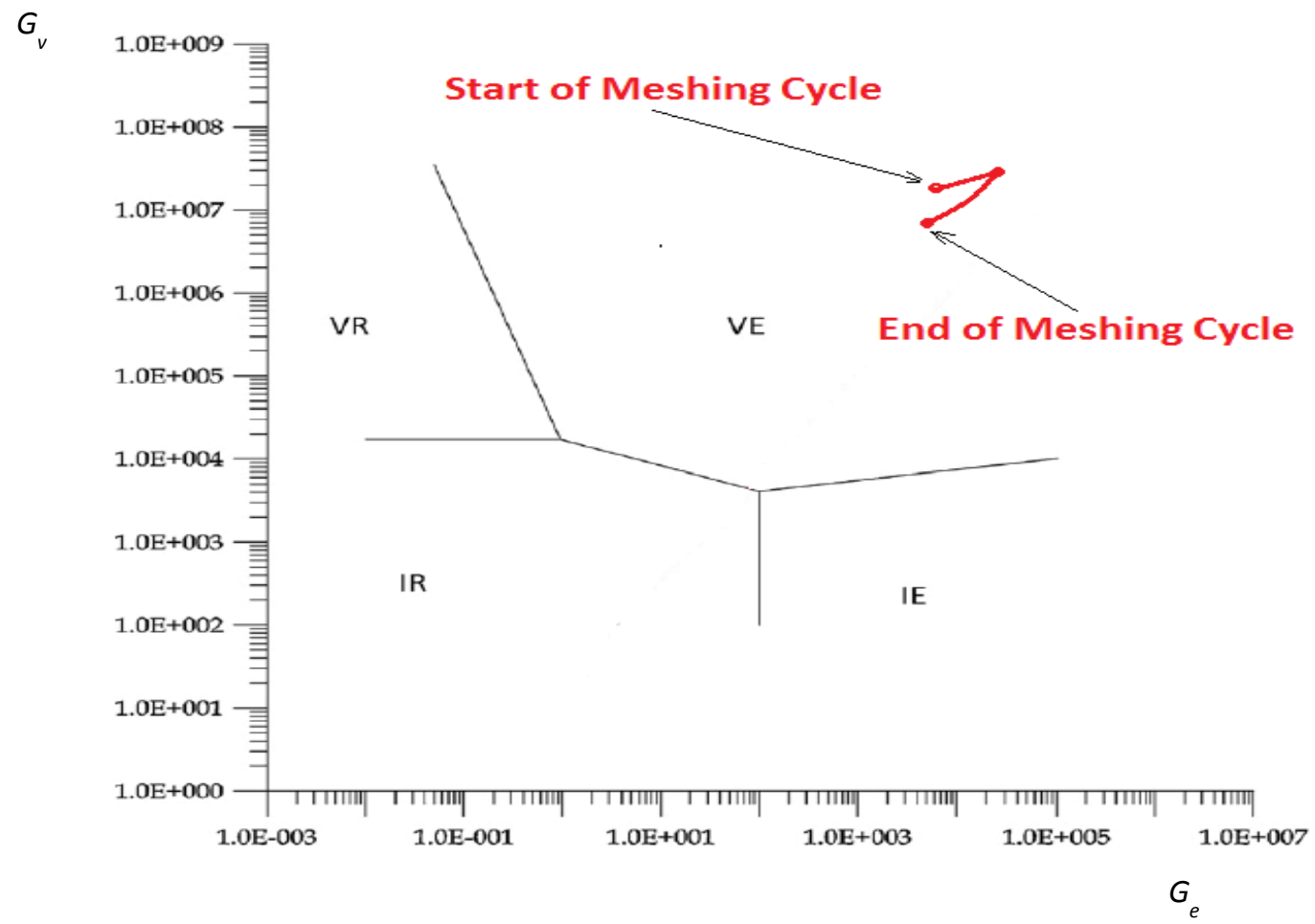

Fig.12 Piezo-viscous (EHL) conditions during teeth pair meshing cycle

Key: IR=Iso-viscous Rigid, IE=Iso-viscous Elastic, VR=Viscous Rigid, $\mathrm{VE}=$ Viscous Elastic (EHL) 


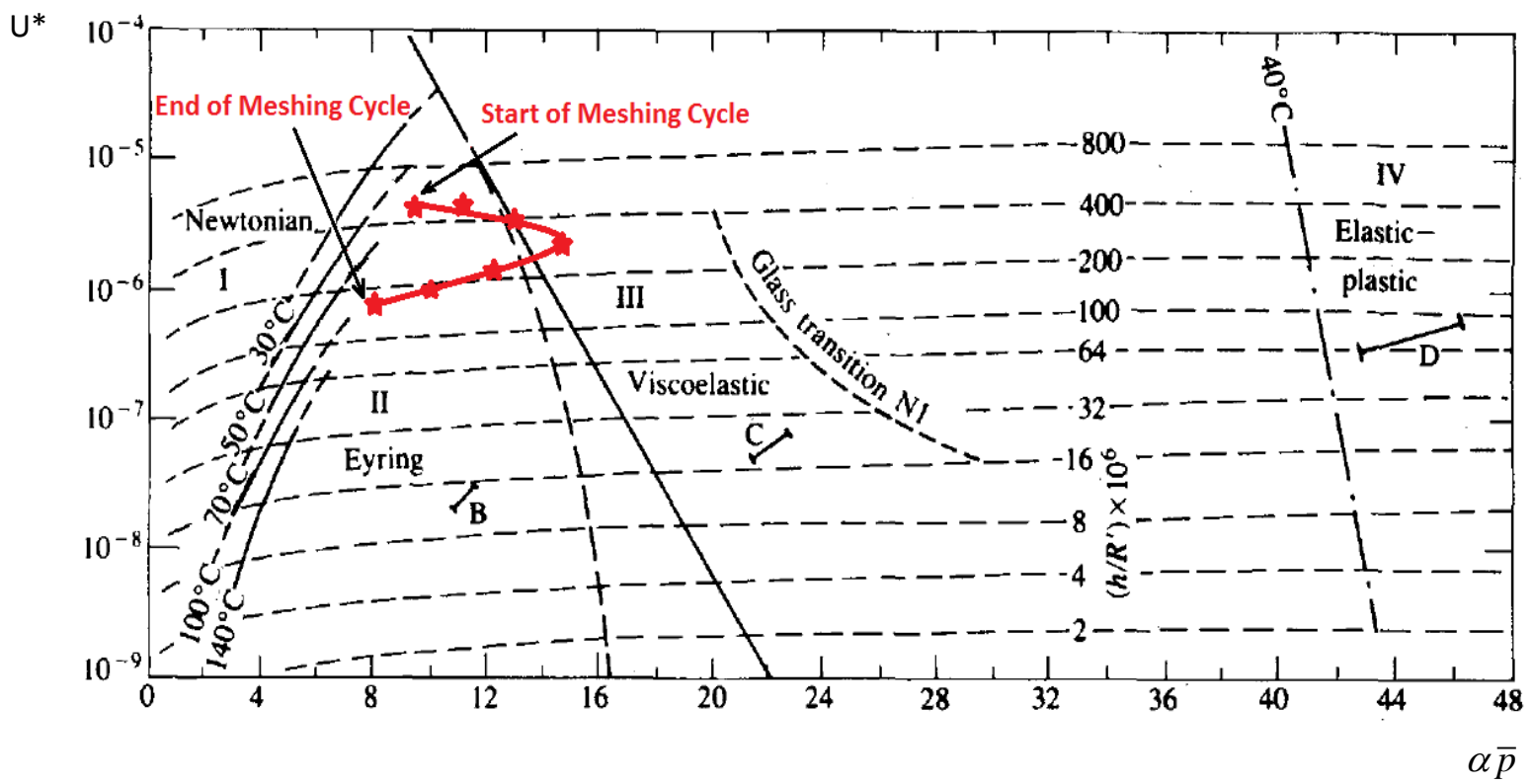

Fig.13 Traction regime in differential gear teeth meshing superimposed on the chart of ref. [36]

Fig. 14 shows the variation of Deborah's number during a meshing cycle for a teeth pair. As it can be seen that its value remains far less than unity, indicating an insufficient time for lubricant relaxation in passage through the contact. Thus, the omission of the elastic behaviour of the lubricant in the current analysis is wellfounded.

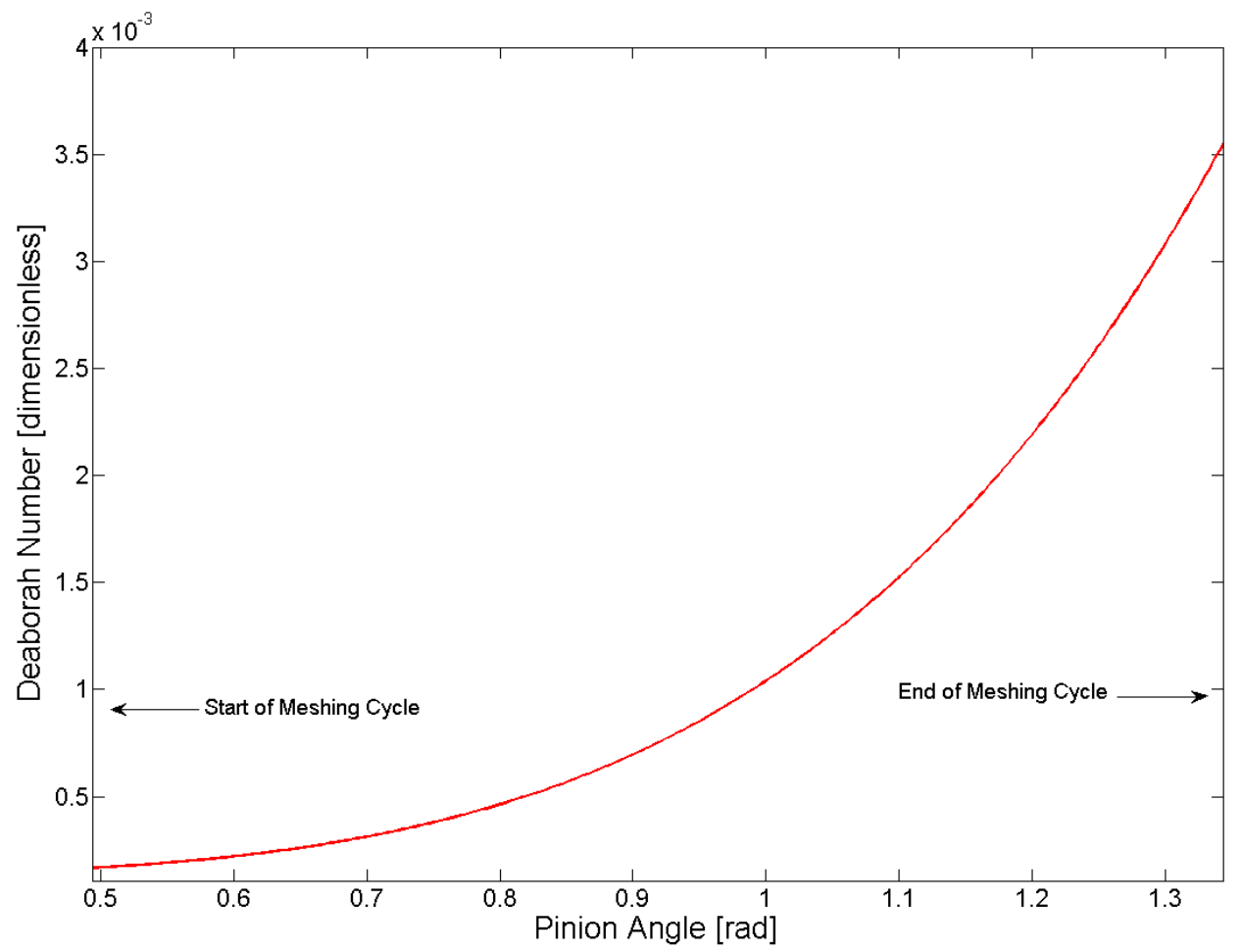

Fig.14 Variation of Deborah Number during a meshing cycle

The main aim of the analysis is to determine the coefficient of friction and thus, the transmission efficiency of the hypoid gear pair. There is a dearth of reported 
analysis in this regard for hypoid gears. For helical gears there has been considerably more research effort, including [59, 60]. For hypoid gears, there have been scoring tests and efficiency measurements by Naruse et al [61] and approximation of power loss for hypoid gears as a combination of spiral bevel gears and a worm gear by Buckingham [62]. These studies have indicated transmission efficiency in the order of $96 \%-98 \%$. A more comprehensive analysis is carried out by $\mathrm{Xu}$ et al [63], who used a combination of TCA and thermoelastohydrodynamics of hypoid gear pairs to predict the coefficient of friction. The lubricant behaviour was assumed to be Newtonian. The coefficient of friction was predicted to be around 0.02-0.03 with transmission mechanical efficiency of 97\%-98\%. Recently an experimental investigation of axle efficiency has been presented by Hurley [64]. This work shows an overall efficiency of 92\% to $98 \%$ for a range of speeds and torques. Essentially, a similar approach is used here but with non-Newtonian lubricant behaviour and angled flow into the contact, thus accounting for the lubricant side leakage from the contact. In addition, mixed regime lubrication is assumed due to thin film thickness and relatively high roughness. Under this condition, viscous shear of the lubricant and boundary interaction of contacting surfaces both contribute to the generated friction as:

$$
f_{r}=f_{v}+f_{b}
$$

To obtain boundary friction, the Greenwood and Tripp [28] model is used. This model assumes a Gaussian distribution of the asperity heights with a mean radius of curvature for the typical asperity summit, $\beta$. In the current study, the plastic deformation of asperities is neglected. Greenwood and Tripp [28] have shown a small difference of $5 \%$ in friction, depending on contact conditions. Therefore, for simplicity, elastic state of asperities is only considered in the current analysis. However, inclusion of plasticity is important if thermal conditions are taken into account with a significant asperity distribution. The area $A_{a}$ of asperity contact and the load $F_{\alpha}$ carried by the asperities may be estimated as:

$$
\begin{gathered}
A_{\alpha}=\pi^{2}(\xi \beta \sigma)^{2} A F_{2}(\lambda) \\
F_{\alpha}=\frac{8 \sqrt{2}}{15} \pi(\xi \beta \sigma)^{2} \sqrt{\frac{\sigma}{\beta}} E^{\prime} A F_{5 / 2}(\lambda)
\end{gathered}
$$

In these formulae $A$ is the apparent contact area and $\xi$ is the density of asperity peaks per unit area. The statistical functions $F_{2}$ and $F_{5 / 2}$ depend on the Stribeck's oil film parameter, $\lambda$ :

$$
F_{n}(\lambda)=\frac{1}{\sqrt{2 \pi}} \int_{\lambda}^{\infty}(s-\lambda)^{n} e^{s^{2} / 2} d s
$$

According to Teodorescu et al [65] the results of numerical integration for these functions of interest and their least square fittings yield: 


$$
\begin{aligned}
& F_{5 / 2}=-0.1922 \lambda^{3}+0.721 \lambda^{2}-1.0649 \lambda+0.6163 \\
& F_{2}=-0.116 \lambda^{3}+0.4862 \lambda^{2}-0.7949 \lambda+0.4999
\end{aligned}
$$

According to Greenwood and Tripp [28], the roughness parameter $\xi_{\beta} \beta \sigma$ is reasonably constant with a value of $0.03-0.05$ for steel surfaces and the ratio $\sigma / \beta$ is in the range $10^{-4}-10^{-2}$ (this being a representation of the average asperity slope [32]). Assuming $\sigma_{1}=\sigma_{2}$, this results in $\xi \beta \sigma=0.04-0.07$ and with an average value of $\xi \beta \sigma=0.055$, the asperity contact area $A_{a}$ becomes:

$$
A_{a}=0.0298 A F_{2}(\lambda)
$$

Considering the same data and assuming that $\sigma / \beta=0.001$, the load carried by the asperities becomes:

$$
F_{a}=0.000227 E^{8} A F_{5 / 2}(\lambda)
$$

The boundary shear stress is obtained as:

$$
\tau_{b}=\tau_{L 0}+\lambda_{p}^{s} p_{a}
$$

where a thin adsorbed film at the summit of an opposing asperity pair acts in nonNewtonian shear at asperity pressure $p_{a}=\frac{F_{a}}{A_{a}}$. Thus:

$$
f_{b}=\int_{A_{t}} \tau_{b} d A_{a}
$$

The viscous friction is calculated as:

$$
f_{v}=\int_{A_{t}} \tau_{v} d A_{v}
$$

where $A_{v}=A-A_{a}$ is the area of full fluid film lubrication. Note that $A_{v}>>A_{a}$. In fact less than $1 \%$ of the overall contact area is found to be that of the asperity contact area. The value of $F_{a}$ is also found to be approximately $1 \%$ of the contact load. However, this small asperity contact area accounts for $2.5-6 \%$ of the overall friction as shown in figure 15. An interesting point to note is that unlike spur and helical gears where there is no sliding motion of gear teeth at the pitch point, thus no viscous friction, the hypoid gear pair contact has no pitch point and 
thus there is no pure rolling motion during the meshing cycle. Under thermal conditions, with thinner lubricant films, one would expect a greater contribution from boundary friction.

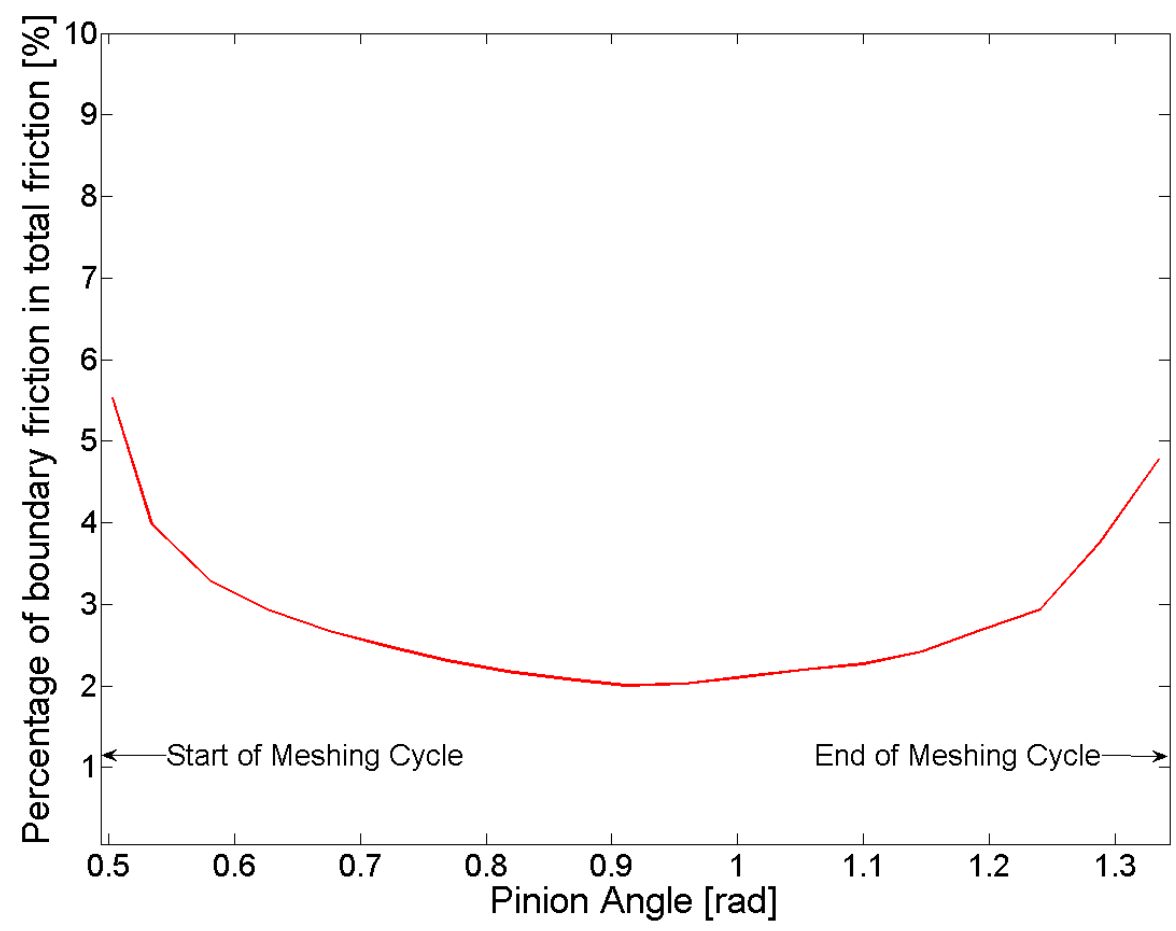

Fig. 15: Boundary friction as a proportion of total friction in mixed regime of lubrication

Fig. 16 shows the variation of coefficient of friction for a teeth pair through a complete meshing cycle. The average value is predicted to be 0.067 . This value is twice that predicted in [63]. The reasons for the difference between these predictions are manifold, including different gear geometries, loading and speed and particularly the assumed inlet boundary conditions (which are fully flooded in [63] but just flooded in the current analysis). In many gearing applications, starvation of the contact occurs for a variety of reasons. They include physical restrictions to lubricant flow rate [66], excessive side leakage of the lubricant from the contact domain $[67,68]$ and in some gearing systems windage (flow of air or vapour around the meshing gears) or attitude and inclination of the transmission [66]. Therefore, it is necessary to take into account inlet boundary conditions which are different to the usually assumed flooded condition. However, it is difficult to predict precise inlet boundary in rolling and sliding contacts with different contiguous surface velocities, which often cause flow reversals at the inlet [69]. Therefore, the current analysis uses inlet boundaries, based upon the generic work of Hamrock and Dowson [22]. The comparison between such an inlet and the fully flooded condition becomes less pronounced, in terms of pressure distribution and friction at high loads, because the prevailing conditions are non-Newtonian with limiting lubricant shear. Under these conditions, the dominant influence on shear, thus friction, is due to pressure rather than Couette shear. Nevertheless, for the sake of completeness, it is important to take into 
account a more realistic inlet boundary than the general assumption of a flooded inlet. Fig.17 shows a comparison between fully flooded and starved conditions. The comparison between pressure and film thickness is also presented.

There is also the inclusion of non-Newtonian lubricant shear and mixed regime of lubrication in the current analysis and inclusion of thermal effects [63].

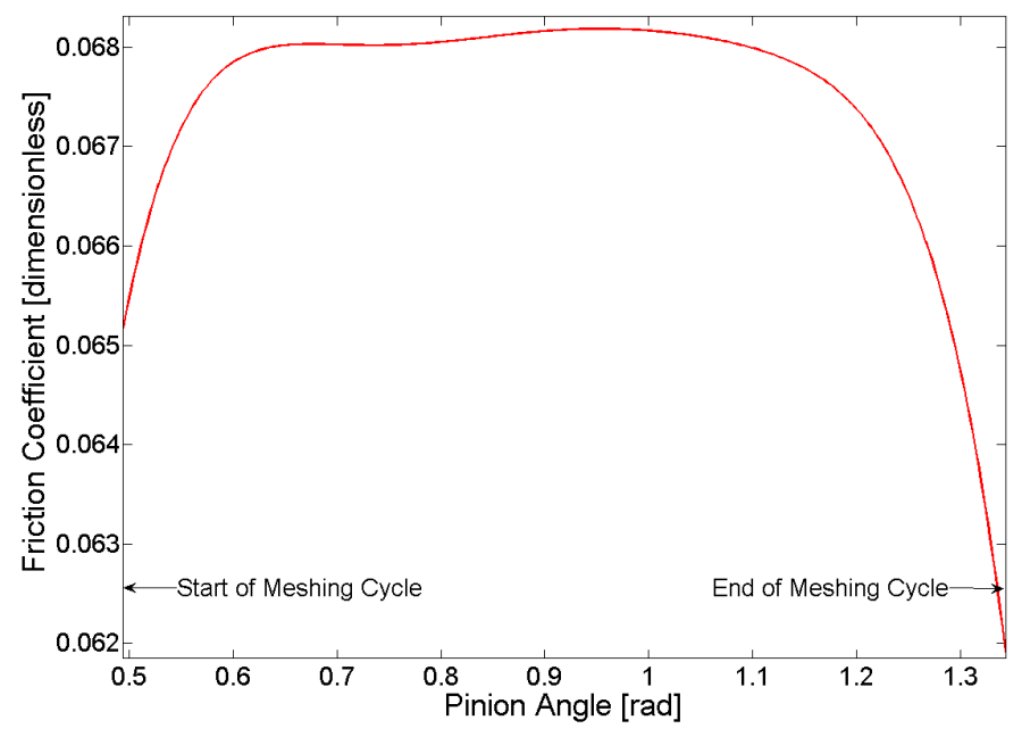

Fig.16 Variation of coefficient of friction during meshing cycle

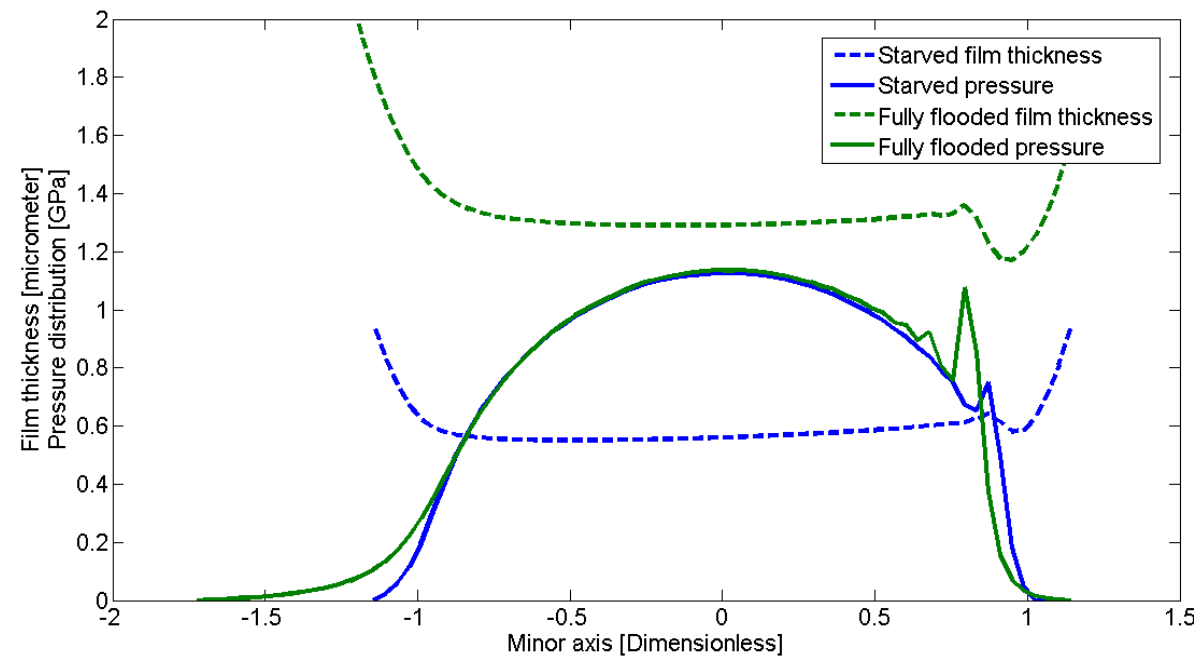

Fig.17 Comparison between flooded and starved conditions (0: centre of Hertzian contact)

However, good agreement is observed when mechanical inefficiency is obtained as the ratio of power loss over the input power, where the power loss is obtained as: $P=f \Delta U$. Fig. 18 shows the percentage inefficiency for the differential hypoid gears, based on the simultaneous meshing of 1-3 conjugate teeth pairs per 
meshing cycle. This indicates a mean mechanical efficiency of $97.9 \%$ (i.e. mean losses of $2.1 \%$ ). The power loss predicted here is within the range of 1-3\%, also predicted by Xu and Kahraman [18] and Kolivand and Kahraman [19].

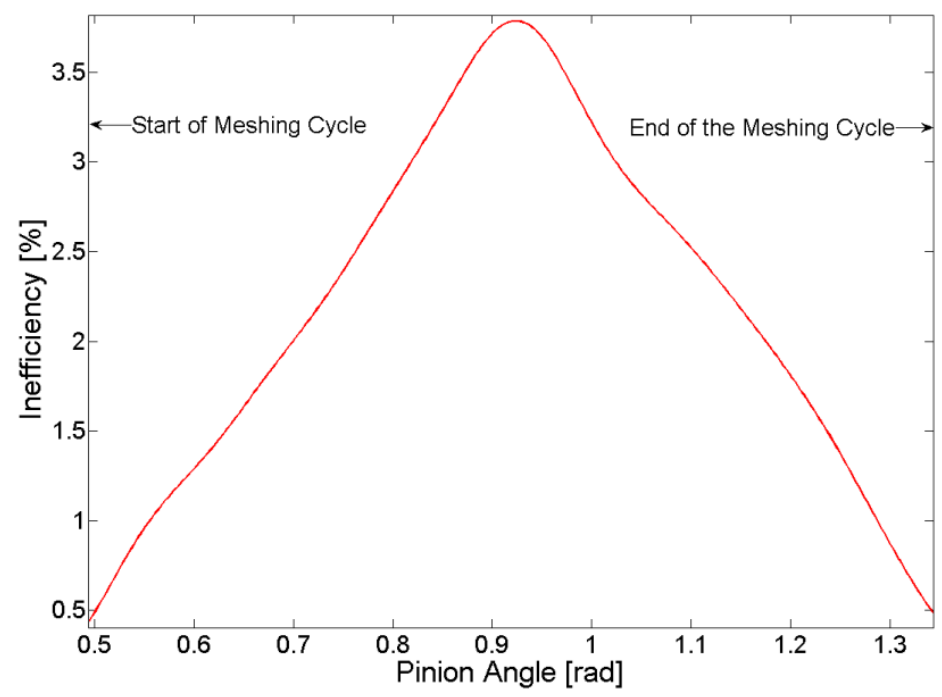

Fig.18 Inefficiency of the differential hypoid gear pair during the meshing cycle

\section{4- Concluding Remarks}

The paper has shown that hypoid gear teeth pairs yield an elliptical footprint contact, where the lubricant entrainment into the contact occurs at an angle to its minor axis. This results in significant side leakage from the contact, which should be taken into account. The contact of differential hypoid gears of automobiles is subject to moderate to high loads, resulting in thin non-Newtonian films under elastohydrodynamic regime of lubrication, which indicates tractive characteristics of an Eyring fluid. The mechanical efficiency of the differential unit as the result of frictional losses alone is on average 97.9\%, which agrees with thermoelastohydrodynamic Newtonian analysis of other research workers. The current analysis is for medium speed range of $\mathrm{C}$-segment class vehicles. It is expected that thinner films may occur at lower engine speeds, resulting in more prominent mixed regime of lubrication. Furthermore, thinner films may also result, if thermal shear heating is taken into account. Therefore, it is intended to expand the current analysis to thermo-elastohydrodynamics with non-Newtonian shear. The devised "combined non-Newtonian model", confining the contact shear stress within the limiting shear of the differential fluid has indicated that at high loads and with significant slide-roll ratio (around 0.4 or above), there may be a tendency for the lubricant relaxation to occur and result in viscoelastic traction. It is intended to extend the analysis to investigate the likely occurrence of such phenomenon in differential gears. 
Acknowledgements Authors would like to express their gratitude to Ford Motor Company for its technical support, as well as to Dr. Vijayakar of Advanced Numerical Solutions Inc., Columbus, Ohio for access to the TCA tool CALYX.

\section{References}

1. Rahnejat H, (2010) Tribology and dynamics of engine and powertrain. Woodhead Publishing Ltd., Cambridge, UK

2. Mehdigoli H, Rahnejat H, and Gohar R, (1990) Vibration response of wavy surfaced disc in elastohydrodynamic rolling contact. Wear, 139(1): 1-15

3. Rahnejat H, (1998) Multi-body Dynamics: Vehicles. Machines and Mechanisms, PEP (IMechE) and SAE (joint publishers), Bury St Edmund, UK and Warrandale, Pa, USA

4. Denny C.M, (1998) Mesh friction in gearing. AGMA, Technical Paper No. 98FTM2

5. Michlin Y, and Myunster. V, (2002) Determination of power losses in gear transmissions with rolling and sliding friction incorporated. Mech.Mach. Theory, 37: $167-174$

6. De la Cruz M, Theodossiades S, and Rahnejat H, (2010) An investigation of manual transmission drive rattle. Proc. Instn. Mech. Engrs., Part K: J. Multi-body Dyn., 224: 167-181.

7. De la Cruz M, Chong W.W.F, Teodorescu M, Theodossiades S, and Rahnejat H, (2012) Transient mixed thermo-elastohydrodynamic lubrication in multi-speed transmissions", Trib. Int., 49: 17-29

8.Misharin Y.A, (1958) Influence of the friction condition on the magnitude of the friction coefficient in the case of rollers with sliding. Proc. Int. Conf. on Gearing, IMechE, London, UK, 159-164

9. Benedict G.H, and Kelly B.W, (1960) Instantaneous coefficients of gear tooth friction. Trans. ASLE, 4: 59-70

10. He S, Gunda R, and Singh R, (2007) Effect of sliding friction on the dynamics of spur gear pair with realistic time-varying stiffness. J. Sound \& Vib., 301: 927949

11. Velex P, and Cahouet. V, (2000) Experimental and numerical investigations on the influence of tooth friction in spur and helical gear dynamics. Trans. ASME, J. Mechanical Design, 122: 515-522. 
12. Velex $P$, and Sainsot $P$, (2002) An analytical study of tooth friction excitations in errorless spur and helical gears. Mechanism and Machine Theory, 37: 641-658.

13. Kar C, and Mohanty A.R, (2007) An algorithm for determination of timevarying frictional force and torque in a helical gear system. Mechanism \& Machine Theory, 42: 482-496

14. Karagiannis. I, Theodossiades S, and Rahnejat H, (2012) On the dynamics of lubricated hypoid gears. Mech. \& Mach. Theory, 48: 94-120

15. Grubin A.N, (1949) Contact stresses in toothed gears and worm gears", Book

30 CSRI for Technology and Mechanical Engineering. Moscow, DSRI Trans., 337

16. Li S, and Kahraman A, (2010) A transient mixed elastohydrodynamic lubrication model for spur gear pairs. Trans. ASME, J. Trib. 132 (1): 011501 (9 pp.)

17. Litvin F. L, Fuentes A, Fan Q, and Handschuh R. F, (2002) Computerized design, simulation of meshing, and contact and stress analysis of face-milled formate generated spiral bevel gears. Mech. \& Mach. Theory, 37: 441-459

18. Xu H, and Kahraman A, (2007) Prediction of friction-related power losses of hypoid gear pairs. Proc. Instn. Mech. Engrs., Part K: J. Multi-body Dyn., 221: $387-400$

19.Kolivand M, Li S, and Kahraman A, (2010) Prediction of mechanical gear mesh efficiency of hypoid gear pairs. Mech. \& Mach. Theory,45: 1568-1582

20. Simon V, (2009) Influence of machine tool setting parameters on EHD lubrication in hypoid gears. Mech. \& Mach. Theory, 44: 923-937

21. Mohammadpour M, Theodossiades S, and Rahnejat H, (2012) Elastohydrodynamic lubrication of hypoid gears at high loads", Proc. Instn. Mech. Engrs., Part J: J. Engng. Tribology, 226 (3):183-198

22. Hamrock B.J, and Dowson D, (1977) Isothermal elastohydrodynamic lubrication of point contacts. Part IV - Starvation results", Trans. ASME, J. Lubn. Tech., 99: 15-23

23. GABICCINI, M.; BRACCI, A.; GUIGGIANI, M. Robust optimization of the loaded contact pattern in hypoid gears with uncertain misalignments. Journal of Mechanical Design, 2010, 132: 041010.

24. Lunin, S.V., "New discoveries in WN gear geometries", www.zakgear.com, 2001

25. Gohar R, (1971) Oil film thickness and rolling friction in elastohydrodynamic point contact. Trans. ASME, J. Lubn. Tech., 93: 371-382 
26. Jalali-Vahid D, Rahnejat H, Gohar R, and Jin Z.M, (2000) Prediction of oilfilm thickness and shape in elliptical point contacts under combined rolling and sliding motion. Proc. Instn. Mech. Engrs., Part J: J. Engng. Trib., 214: 427-437

27.Bair S, and Winer W. O, (1979) Shear strength measurements of lubricants at high loads. Trans. ASME, J. Lubn. Tech., 101: 251-257

28. Greenwood J. A, and Tripp J. H, (1970) The contact of two nominally flat rough surfaces. Proc. Instn. Mech. Engrs, 185: 625-633

29. Vijayakar S, (2000) CALYX Manual. Advanced Numerical Solutions Inc., Columbus, Ohio

30. Johnson K. L, and Tevaarwerk J. L, (1977) Shear behaviour of elastohydrodynamic oil films. Proc. R. Soc. Lond., A- 356: 215-236

31. Olver A.V, and Spikes H.S, (1998) Prediction of traction in elastohydrodynamic lubrication. Proc. Instn. Mech. Engrs., Part J: J. Engng. Tribology, 212: 321-332

32. Gohar R, and Rahnejat H, (2008) Fundamentals of Tribology. Imperial College Press, London

33. Eyring H, (1936) Viscosity, plasticity and diffusion as examples of absolute reaction rates. J. Chem. Phys., 4: 283

34. Hirst W, and Moore A. J, (1974) Non-Newtonian behaviour in elastohydrodynamic lubrication. Proc. R. Soc. Lond., 337: 101-121

35. Hamilton G. M, and Moore S. L, (1971) Deformation and pressure in an elastohydrodynamic contact. Proc. R. Soc. Lond., 322 (1550): 313-330

36. Evans C. R, and Johnson K. L, (1986) Regimes of Traction in EHD Lubrication' Proc. Instn. Mech. Engrs., Part C: J. Mech. Engng. Sci., 200: 313324

37. Hirst W, and Moore A. J, (1979) Elastohydrodynamic lubrication at high pressures II: Non-Newtonian behaviour. Proc. R. Soc. Lond., 365: 537-565

38. Lee R. T, and Hamrock B. J, (1990) A circular non-Newtonian fluid model, Part I, Used in elastohydrodynamic lubrication. Trans. ASME, J. Trib., 112: 486496

39. Crook A. W, (1961) The lubrication of rollers III: A theoretical discussion of friction and the temperatures in the oil film", Proc. R. Soc. Lond. , 254 (1040):237-258

40. Johnson K.L, and Greenwood J. A, (1980) Thermal analysis of an Eyring fluid in elastohydrodynamic traction. Wear, 61: $353-374$ 
41. Spikes H.A, Olver A.V, and Macpherson P.B, (1986) Wear in rolling contacts", Wear, 112(2): 121-144

42. Conry T. F, Wang S, and Cusano C, (1987) A Reynolds-Eyring equation for elastohydrodynamic lubrication in line contacts. Trans. ASME, J. Trib., 109: 648658

43. Wang S, Cusano C, and Conry T. F, (1991) Thermal analysis of elastohydrodynamic lubrication of line contacts using the Ree-Eyring fluid model", Trans. ASME,J. Trib., 113: 232-244

44.Kim K. H, and Sadeghi F, (1991) Non-Newtonian elastohydrodynamic lubrication of point contacts.”, Trans. ASME, J. Trib., 113: 703-711

45. Teodorescu, M., Votsios, V., Rahnejat, H., and Taraza, D. (2006). Jounce and impact in cam-tappet conjunction induced by the elastodynamics of valve train system. Meccanica, 41(2), 157-171.

46. Ciulli, E. (2009). Non-steady state non-conformal contacts: friction and film thickness studies. Meccanica, 44(4), 409-425.

47. Briscoe, B. J., and Evans, D. C. B. (1982). The shear properties of LangmuirBlodgett layers. Proceedings of the Royal Society of London. A. Mathematical and Physical Sciences, 380(1779), 389-407.

48. Patir, N. and Cheng, H.S. (1978), "An average flow model for determining effects of three-dimensional roughness on partial hydrodynamic lubrication", Trans. ASME, Series F: J. Lubn. Tech.100, pp.12-17.

49. Roeland C.J.A, (1966) Correlation aspect of the viscosity-temperaturepressure relation of lubrication oils, PhD Thesis, Delft University of Technology, The Netherlands

50. Dowson D, and Higginson G.R, (1959) A numerical solution to the elastohydrodynamic problem. Proc. Instn. Mech. Engrs., J. Mech. Engng. Sci., 1: 6-15

51. Birkhoff J, and Hays D.F, (1963) Free boundaries in partial lubrication. J. Math. \& Phys., 32: 2

52. Gohar R, (2001) Elastohydrodynamics, Imperial College Press, London

53. Ali, F., Křupka, I., \& Hartl, M. (2013). Analytical and experimental investigation on friction of non-conformal point contacts under starved lubrication. Meccanica, 48(3), 545-553.

54. Swift H.W, (1932) The wetability of lubricating films in journal bearings. Minutes of the Proc., J. Instn. Civ. Engrs., 223: 267-288 
55. Stieber W, (1933) Das schwimmlager: Hydrodynamische theorie des gleitlagers. VDI-Verlag

56. Vaishya M, and Singh R, (2001) Analysis of periodically varying gear mesh systems with Coulomb friction using Floquet theory", J. Sound \& Vib., 243: 525545

57. Jalali-Vahid D, Rahnejat H, Jin Z.M, and Dowson D, (2001) Transient analysis of isothermal elastohydrodynamic circular point contacts. Proc. Instn. Mech. Engrs., J. Mech. Engng. Sci., 215: 1159-1172

58. Bair S, (2001) The variation of viscosity with temperature and pressure for various real lubricants. Trans. ASME, J. Tribology, 123: 433-436

59. Akin L. S, (1974) EHD lubricant film thickness formulae for power transmission gears", Trans. ASME, J. Lubn.Tech., 426-431

60. Simon V, (1988) Thermo-EHD analysis of lubrication of helical gears. Trans. ASME, J. Mech. Design, 110: 330-336

61. Naruse C, Haizuka S, Nemoto R, and Umezu T, (1986) Limiting loads for scoring and frictinal loss of hypoid gear. Bull. JSME, 29(253): 2271-2280

62. Buckingham E, (1963) Efficiencies of Gears in Analytical Mechanics of Gears, Dover, New York, 395-425

63. Xu H, Kahraman A, and Houser D.R, (2005) A model to predict friction losses of hypoid gears. AGMA Tech. Pap.: 05FTM06

64. Hurley J. D, (2009) An experimental investigation of thermal behaviour of an automotive rear axle. MSc thesis, The Ohio State University

65. Teodorescu M, Taraza D, Henein N. A, and Bryzik W, (2003) Simplified elasto-hydrodynamic friction model of the cam - tappet contact. Trans. SAE, J. Engine., 1271-1283

66. Olver, A. V. (2002). Gear lubrication-a review. Proceedings of the Institution of Mechanical Engineers, Part J: Journal of Engineering Tribology, 216(5), 255-267.

67. Evans, H. P., \& Snidle, R. W. (1982). The elastohydrodynamic lubrication of point contacts at heavy loads. Proceedings of the Royal Society of London. A. Mathematical and Physical Sciences, 382(1782), 183-199.

68. Evans, H. P., \& Snidle, R. W. (1983). Analysis of elastohydrodynamic lubrication of elliptical contacts with rolling along the major axis. Proceedings of the Institution of Mechanical Engineers, Part C: Journal of Mechanical Engineering Science, 197(3), 209-211. 
69. Tipei N, (1968) Boundary Conditions of a Viscous Flow Between Surfaces

With Rolling and Sliding Motion. Trans. ASME, J. Lubn. Tech., 90 (1): 254-261

\section{Figures captions:}

Fig.1 Representation of an elliptical point contact conjunction with angled entrainment flow

Fig.2 Contact Geometry of the equivalent ellipsoidal solid

Fig.3 Starvation boundaries along minor and major axes

Fig.4 Contact footprint and direction of angled flow

Fig.5 The processing elliptical footprint through a meshing cycle

Fig.6 Grid convergence of the model

Fig.7 Contact kinematics under prescribed differential running conditions

Fig.8 Three dimensional elastohydrodynamic pressure distribution (position of maximum contact load)

Fig.9 Lubricant film contour (position of maximum contact load)

Fig.10 Elastohydrodynamic film shape along the section $\mathrm{X}-\mathrm{X}^{\prime}$ under Newtonian and non-Newtonian shear

Fig.11 Shear stress variation within the contact at the maximum meshing load

Fig.12 Piezo-viscous (EHL) conditions during teeth pair meshing cycle

Fig.13 Traction regime in differential gear teeth meshing superimposed on the chart of ref. [33]

Fig.14 Variation of Deborah Number during a meshing cycle

Fig. 15: Boundary friction as a proportion of total friction in mixed regime of lubrication

Fig.16 Variation of coefficient of friction during meshing cycle

Fig.17 Comparison between flooded and starved conditions (0: center of Hertzian contact)

Fig.18 Inefficiency of the differential hypoid gear pair during the meshing cycle 
Tables:

Table 1a: Gear pair parameters

\begin{tabular}{|l|l|}
\hline Pinion parameters: & \\
\hline Number of pinion teeth & 13 \\
\hline Pinion face-width (mm) & 33.851 \\
\hline Pinion face angle (deg) & 29.056 \\
\hline Pinion pitch angle (deg) & 29.056 \\
\hline Pinion root angle (deg) & 29.056 \\
\hline Pinion spiral angle (deg) & 45.989 \\
\hline Pinion pitch apex (mm) & -9.085 \\
\hline Pinion face apex (mm) & 1.368 \\
\hline Pinion Outer cone distance (mm) & $\mathbf{8 3 . 0 8 4}$ \\
\hline Pinion offset (mm) & 24.0000028 \\
\hline Pinion hand & Right \\
\hline
\end{tabular}

\begin{tabular}{|l|l|}
\hline Gear parameters: & \\
\hline Number of gear teeth & 36 \\
\hline Gear face width (mm) & 29.999 \\
\hline Gear face angle (deg) & 59.653 \\
\hline Gear pitch angle (deg) & 59.653 \\
\hline Gear root angle (deg) & 59.653 \\
\hline Gear spiral angle (deg) & 27.601 \\
\hline Gear pitch apex (mm) & $\mathbf{8 . 9 8 7}$ \\
\hline Gear face apex (mm) & 10.948 \\
\hline Gear Outer cone distance (mm) & 95.598 \\
\hline Gear offset (mm) & 24 \\
\hline
\end{tabular}


Table 1b: Properties of contacting solids and lubricant

\begin{tabular}{|l|l|}
\hline Pressure viscosity coefficient $(\boldsymbol{\alpha})$ & $2.19 \mathrm{e}-8[\mathrm{~Pa}-1]$ \\
\hline Atmospheric dynamic viscosity $\left(\eta_{0}\right)$ & $\mathbf{0 . 0 8}[\mathrm{Pa} . \mathbf{s}]$ \\
\hline Inlet density $\rho_{0}$ & $\mathbf{8 4 6}[\mathrm{kg} / \mathrm{m3}]$ \\
\hline Modulus of elasticity of contacting solids & $\mathbf{2 1 0}[\mathrm{GPa}]$ \\
\hline Poisson's ratio of contacting solids & $\mathbf{0 . 3}[-]$ \\
\hline Eyring shear stress $\left({ }^{\tau_{0}}\right)$ & $\mathbf{5}(\mathrm{MPa})$ \\
\hline Atmospheric limiting shear stress $\left({ }^{\tau_{L 0}}\right)$ & $\mathbf{2 . 3}(\mathrm{MPa})$ \\
\hline Pressure-induced shear coefficient $\left(\lambda^{\prime}\right)$ & $\mathbf{0 . 0 4 7}$ \\
\hline
\end{tabular}


Table 2: Equivalent geometry, load share and kinematics of a teeth pair through mesh

\begin{tabular}{|c|c|c|c|c|c|c|}
\hline $\begin{array}{l}\text { pinion } \\
\text { angle } \\
\varphi \text { (Rad) }\end{array}$ & $\begin{array}{l}\text { Contact } \\
\text { load } \\
F(\mathbf{k N})\end{array}$ & $\begin{array}{l}\text { Magnitude } \\
\text { of } \\
\text { entraining } \\
\text { velocity } \\
{[\mathrm{m} / \mathrm{s}]}\end{array}$ & $\begin{array}{l}\text { Velocity } \\
\text { along the } \\
\text { minor } \\
\text { axis } \\
U \sin \theta \\
(\mathbf{m} / \mathbf{s})\end{array}$ & $\begin{array}{l}\text { Velocity } \\
\text { along the } \\
\text { major axis } \\
U \cos \theta_{(\mathrm{m} / \mathrm{s})}\end{array}$ & $\begin{array}{l}\text { Principal } \\
\text { radius } R_{z x} \\
\text { (m) }\end{array}$ & $\begin{array}{l}\text { Principal } \\
\text { radius } \\
R_{z y}(\mathbf{m})\end{array}$ \\
\hline 0.5027 & 0.59 & 12.78 & 11.46 & 5.65 & 0.0157 & 1.0067 \\
\hline 0.5341 & 0.93 & 12.66 & 11.31 & 5.69 & 0.0158 & $\mathbf{1 . 0 2 9 7}$ \\
\hline 0.5812 & 1.34 & 12.48 & 11.07 & 5.75 & 0.0160 & 1.0626 \\
\hline 0.6283 & 1.73 & 12.30 & 10.84 & 5.81 & 0.0162 & 1.0937 \\
\hline 0.6754 & 2.15 & 12.13 & 10.61 & 5.88 & 0.0164 & 1.1228 \\
\hline 0.7226 & 2.61 & 11.97 & 10.37 & 5.95 & 0.0166 & 1.1501 \\
\hline 0.7697 & 3.11 & 11.80 & 10.14 & 6.03 & 0.0168 & 1.1754 \\
\hline 0.8168 & 3.68 & 11.64 & 9.91 & 6.11 & 0.0171 & 1.1988 \\
\hline 0.8639 & 4.22 & 11.49 & 9.67 & 6.19 & 0.0174 & 1.2204 \\
\hline 0.9111 & 4.71 & 11.34 & 9.44 & 6.28 & $\mathbf{0 . 0 1 7 7}$ & 1.2400 \\
\hline 0.9582 & 4.56 & 11.20 & 9.21 & 6.36 & 0.0180 & 1.2578 \\
\hline 1.0053 & 4.02 & 11.05 & 8.97 & 6.45 & 0.0183 & 1.2736 \\
\hline 1.0524 & 3.59 & 10.92 & 8.74 & 6.55 & 0.0186 & 1.2876 \\
\hline 1.0996 & 3.21 & 10.78 & 8.50 & 6.64 & $\mathbf{0 . 0 1 9 0}$ & 1.2996 \\
\hline 1.1467 & 2.81 & 10.66 & 8.26 & 6.73 & 0.0194 & 1.3098 \\
\hline 1.1938 & 2.36 & 10.53 & 8.02 & 6.83 & 0.0198 & 1.3180 \\
\hline 1.2409 & 1.87 & 10.42 & 7.78 & 6.92 & 0.0202 & 1.3243 \\
\hline 1.2881 & 1.31 & 10.30 & 7.54 & 7.03 & 0.0206 & 1.3288 \\
\hline 1.3352 & 0.74 & 10.19 & 7.29 & 7.12 & 0.0211 & 1.3313 \\
\hline
\end{tabular}


Appendix:

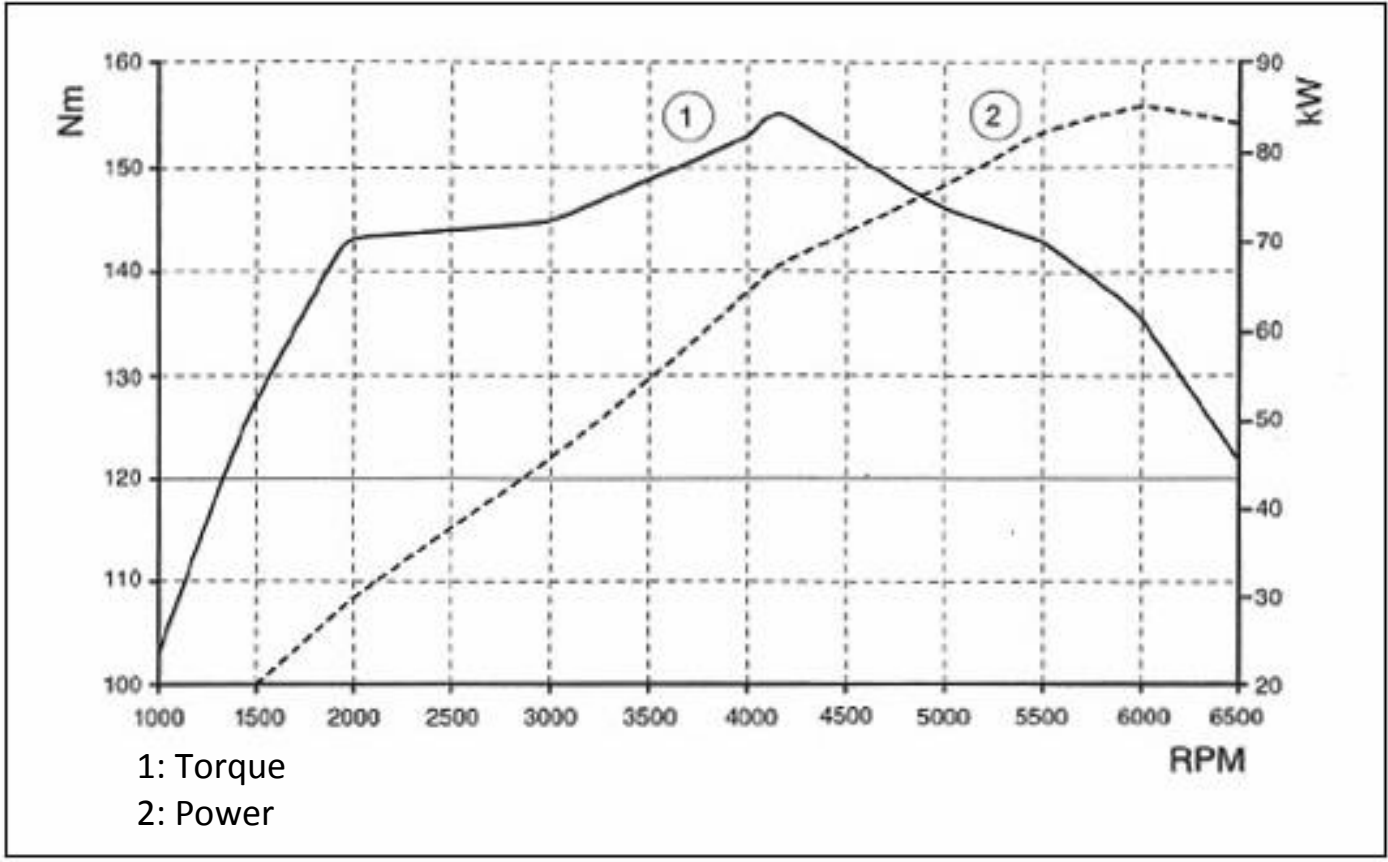

Fig.18 Sample engine map 